\title{
Diazotroph diversity associated with scleractinian corals and its relationships with environmental variables in the South China Sea
}

Jiayuan Liang

Guangxi University

Kefu Yu ( $\square$ kefuyu@scsio.ac.cn )

Guangxi University https://orcid.org/0000-0003-3409-9945

Yinghui Wang

Guangxi University

Xueyong Huang

Guangxi University

Wen Huang

GuangXi University

Zhenjun Qin

GuangXi University

Guanghua Wang

GuangXi University

Hongfei Su

Guangxi University

Biao Chen

Guangxi University

Zhengchao Wu

Chinese Academy of Sciences

Research article

Keywords: Coral reef ecosystem, Associated diazotrophs, nifH gene, Geographical differences, Different latitudes

Posted Date: November 22nd, 2019

DOI: https://doi.org/10.21203/rs.2.17643/v1

License: (c) (1) This work is licensed under a Creative Commons Attribution 4.0 International License.

Read Full License 

3

4 Jiayuan Liang ${ }^{1-3}$, Kefu $\mathrm{Yu}^{1-3^{*}}$, Yinghui Wang ${ }^{1-3}$, Xueyong Huang ${ }^{1-3}$, Wen Huang ${ }^{1-3}$, Zhenjun Qin $^{1-3}$,

5 Guanghua Wang ${ }^{1-3}$, Hongfei Su${ }^{1-3}$, Biao $\mathrm{Chen}^{1-3}$, Zhengchao $\mathrm{Wu}^{4}$

6

$7 \quad{ }^{*}$ Corresponding author, E-mail address: kefuyu@scsio.ac.cn (K. Yu), Tel \& Fax: +86-771-3231358,

8 ORCID number: 0000-0003-3409-9945

$9{ }^{1}$ Coral Reef Research Center of China, Guangxi University, Nanning 530004, China.

10

${ }^{2}$ Guangxi Laboratory on the Study of Coral Reefs in the South China Sea, Nanning 530004, China

${ }^{3}$ School of Marine Sciences, Guangxi University, Nanning 530004, China

${ }^{4}$ State Key Laboratory of Tropical Oceanography (LTO), South China Sea Institute of Oceanology,

Chinese Academy of Sciences, Guangzhou 510301, China 4 (15) 6 8 19 


\section{Abstract}

Background: Coral reef ecosystems cannot operate normally without an effective nitrogen cycle. For oligotrophic coral reef areas, coral-associated diazotrophs are indispensable participants in the nitrogen cycle. How coral-associated diazotrophs will change in order to adapt to environmental changes resulting from global warming and human activities is a topic of concern for researchers. To this end, 68 colonies of scleractinian coral were collected from 6 coral reefs areas with different environmental variables in the South China Sea to investigate the composition of associated diazotrophs based on nifH gene amplification using high-throughput sequencing. The six coral reefs can be clearly divided into two types (fringing reefs and island reefs), are affected by varying degrees of human activities and are located at different latitudes from $9^{\circ} 20^{\prime} 06^{\prime \prime} \mathrm{N}$ to $22^{\circ} 34^{\prime} 55^{\prime \prime} \mathrm{N}$ with different seawater temperatures.

Results: Alpha- and beta-diversity analyses showed that the distribution of diazotrophs among coral reefs exhibited greater geographical fluctuations than interspecific fluctuations. The predominant bacterial phyla included Proteobacteria, Chlorobi, Cyanobacteria, and two unclassified phyla. Chlorobi exhibited an abundance of $47-96 \%$ in coral samples from the high-latitude Daya Bay fringing reef affected by eutrophication. Unclassified bacteria II, with an abundance of $28-87 \%$, was found in all coral samples from the midlatitude Luhuitou fringing reef affected by eutrophication. However, unclassified bacteria I and Proteobacteria dominated (> $80 \%$ abundance) in most of the coral samples from the Weizhou Island fringing reef, which is far from land, and three island reefs (Huangyan Island, Xinyi Reef, and Sanjiao Reef) at relatively low latitudes. At the genus level, some core diazotrophs were found in different coral sample groups. In addition, the correlation analysis with various environmental variables revealed that the variables correlated positively or negatively with different diazotrophic genera. 
Conclusions: We found that coral-associated diazotrophs were common among coral individuals. The

46

47

48

49

50

51

52

53

54

55

56

57

59

61

62 63

64

65

66 60

presence of these diazotrophs was not affected by the external environment, but their population abundances were closely related to the different environmental variables. These results provide insights into the ecological characteristics of coral-associated diazotrophs and their relationships with critical environmental variables in the South China Sea.

Keywords: Coral reef ecosystem, Associated diazotrophs, nifH gene, Geographical differences,

\section{Different latitudes}

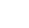

4

5

(1)

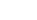

\section{8 8} 59 61 62

\section{4}

\section{5} 66 


\section{Background}

Although coral reef ecosystems are located in oligotrophic seas, their biodiversity and primary productivity are extremely high [1]. This is mainly due to the efficient biogeochemical cycles of carbon, nitrogen, phosphorus, and other basic elements in which coral symbiotic microbes participate [2]. In an ocean environment with very low concentrations of nutrients, the primary productivity of coral reefs is often limited by available nitrogen, which is one of the primary nutrients essential for the survival of all living organisms [3, 4]. The nitrogen fixation system of coral-associated diazotrophs (reduction of $\mathrm{N}_{2}$ to ammonia) is considered the major source of available nitrogen in coral reef waters $[5,6]$. Previous studies have shown that coral reefs have their own internal nitrogen circulation system and protection mechanism [7, 8]. In addition, abundant nitrogen-fixing bacteria associated with corals have been detected in different coral compartments, including mucus [9, 10], tissue [11, 12], and skeleton [7, 13]. In addition, some studies predicted that diazotrophs associated with corals not only provided sufficient nitrogen sources for coral symbionts but also supplied approximately $6 \%$ of organic nitrogen for the whole coral reef ecosystem when the available nitrogen was low $[14,15]$. Recent studies found that coral-associated diazotrophs could significantly respond to human-induced environmental changes, thermal stress, and coral bleaching. For example, the key physiological traits of coral hosts, zooxanthellae, and diazotrophs associated with Stylophora pistillata show less resilience to thermal stress than those associated with Acropora hemprichii. These results revealed a drastic increase in dinitrogen fixation in daylight, particularly in A. hemprichii, which was more resilient to thermal stress than S. pistillata. The results also suggested that coral-associated diazotrophs play an important role in coral holobiont responses to ocean warming [16]. The relationship between bleaching mortality and nitrogen fixation rates of diazotrophs in the coral Acropora aspera showed that $\mathrm{N}_{2}$ fixation rates in 
dead colonies (caused by thermal or cold bleaching) were up to 30 times greater than those measured in live colonies [8].

Currently, the following three main routes are involved in the provision of nitrogen to coral reef ecosystems: (1) terrestrial input, (2) input from ocean currents with rich nutrients, and (3) nitrogen fixation by diazotrophs in the coral reef ecosystems $[12,17-20]$. However, isotope ( $\delta 13 \mathrm{C}$ and $\delta 15 \mathrm{~N})$ tracer experiments showed that the sources of nitrogen for the primary producers in coral reefs (in Palau and Ishigaki) were mainly derived from biological nitrogen fixation [20]. Furthermore, the photosynthetic fixation of $\mathrm{CO}_{2}$ occurred simultaneously with the absorption and fixation of new nitrogen. This suggested that biological nitrogen fixation plays an important role in the assimilation of carbon and nitrogen by the whole coral reef ecosystem.

Recently, diazotrophic communities associated with different coral species, including S. pistillata and A. hemprichii [16], Cladopsammia gracilis and Porites sp. [21], and Montipora capitata and Montipora flabellata [5], among others [13, 22, 23], were investigated. These coral species were investigated in different geographical locations, including the Great Barrier Reef (Kelso Reef, Knife Reef, and Davies Reef), the Luhuitou fringing reef of Sanya Bay (South China Sea), the Marine Science Station in Aqaba (Jordan), the Gulf of Aqaba (Red Sea), Leleiwi Reef (Hawaii Island), Green Island (southeastern Taiwan), and so on. However, how the coral-associated diazotrophs will change in order to adapt to environmental changes associated with global warming and eutrophication caused by human activities remains unclear.

In the South China Sea, there is a large area of coral reefs at a latitudinal range of $4-21^{\circ} \mathrm{N}$ [24]. These coral reefs have long been affected by extreme marine events, human activities, and geographical climates [24-26]. These scleractinian corals can adapt to different environments and 
111

112

113

establish a unique holobiont $[27,28]$. Therefore, coral reefs in the South China Sea are natural laboratories with which to study the patterns of coral-associated diazotroph responses to global warming and eutrophication caused by human activities. To this end, 68 scleractinian coral colonies were collected from 6 geographical locations at different latitudes and with different eutrophication levels in the South China Sea to investigate the composition of coral-associated diazotrophs. It is beneficial to understand the environmental adaptability of coral reefs and the possible changes in coral-associated diazotrophs in the face of climate change and human activities.

\section{Results}

\section{Diversity of coral-associated diazotrophs}

A total of 1,223,398 reads recovered from 68 coral samples, with lengths ranging from 421 to $440 \mathrm{bp}$, were obtained from the sequencing database. Good's coverage of each sequencing database was more than 99\% (Additional file 1: Table S1). Thus, these sequencing results accurately represented the diazotrophs in the coral samples. Other indices, including the abundance-based coverage estimator (ACE) and Shannon index, are shown more intuitively in Fig. 1. The detailed data showed that the ACE, which reflects community richness, varied greatly among coral samples (Additional file 1: Table S1). The lowest values were 21.35, 30.79, and 31.54, from Pv3_Lht, P11_SjR, and P12_SjR, respectively, while the highest values were 300.4, 293.57, and 286.85, from Gr3_XyR, Fp3_WzI, and Ar3_XyR, respectively. The Shannon index (Additional file 1: Table S1), which reflects community diversity, also differed significantly among coral samples (ranging from 0.58 to 4.48). When corals of different species (CDSs) and corals from different reef regions (CDRs) were grouped, these indices showed few significant differences between most CDSs but significant differences between most CDRs (Fig. 1). 
133

Sanjiao Reef $(\mathrm{SjR})(146.99,139.83,145.23$, and 102.12, respectively) were obviously higher than those for Luhuitou (Lht) and Daya Bay (DyB) (71.07 and 75.54, respectively). Meanwhile, the average Shannon values for WzI, HyI, and XyR (3.34, 2.76, and 2.70, respectively) were also higher than those for DyB, SjR, and Lht (1.98, 1.82, and 1.70, respectively). However, the ACE and Shannon index averages for different coral species ranged from 101.73 to 150.28 and 2.12 to 2.73 , respectively, with a small range of fluctuations between them (Fig. 1B and D). These findings suggest that geographical factors have a strong effect on the community richness and diversity of coral-associated diazotrophs.

The number of operational taxonomic units (OTUs) and diversity at various taxonomic levels are listed in Table 1. The results showed significant differences in the number of communities of diazotrophs between coral individuals, even for the same coral species in the same sampled location. For example, 6 phyla, 21 genera, and 280 OTUs were detected in Gr3_XyR, but the numbers were 5, 11 , and 50 in Gr1_XyR, respectively.

\section{Clustering of coral-associated diazotrophs based on similarity}

The similarity among the diazotrophic communities associated with 68 coral samples from 6 locations was evaluated using principal coordinate analysis (PCoA) at the OTU level. The diazotrophic composition of coral individuals differed between coral reefs, whether or not the coral individuals were of the same species (Fig. 2A). In comparison with the grouping of regions, coral individuals from the same species did not cluster together significantly (Fig. 2B). This indicated that the diazotrophic composition associated with corals was somewhat species specific. Overall, the most significant factor affecting diazotrophic composition was geographical position, rather than interspecific differences.

\section{Composition of diazotrophs associated with corals}

Eleven bacterial phyla capable of nitrogen fixation, including 3 unclassified bacteria (I, II, and III), 
155

were identified from the sequencing database of 68 coral samples (Fig. 3). Among these phyla, unclassified bacteria I, with a very high abundance, was present in almost all the coral samples. In addition, the dominant bacterial phyla were Proteobacteria, Chlorobi, and Cyanobacteria. The abundance of these coral-associated bacterial phyla exhibited significant differences between coral reefs. For example, unclassified bacteria I and Proteobacteria were the dominant bacterial phyla $(>80 \%$ abundance) in most of the coral samples from WzI, HyI, XyR, and SjR. In contrast, the abundance of these two bacterial phyla was low $(<35 \%$ abundance $)$ in most of the coral samples from Lht and DyB. In particular, the abundance of Proteobacteria was generally very low $(<10 \%)$ in most of the coral samples from the two locations; the dominant diazotrophs in these locations were unclassified bacteria II (Lht) and Chlorobi (DyB). Of course, there were special cases. For example, the abundance of Chlorobi, the dominant group, was $84 \%$ in P13_SjR from SjR. Unclassified group II was the dominant group, with an abundance of $89 \%$, in $\mathrm{Hm} 1 \_\mathrm{SjR}$ from $\mathrm{SjR}$. Cyanobacteria, members of which are capable of nitrogen fixation, was also a common bacterial phylum in these coral samples. Its abundance ranged from $0.21 \%\left(\mathrm{Pl} 2 \mathrm{SjR}, \mathrm{Pl3} \_\mathrm{Lht}, \mathrm{Pv} 3 \_\right.$Lht, etc.) to 51\% (P15_HyI). The other nitrogen-fixing groups, including Euryarchaeota, Firmicutes, and Verrucomicrobia, were detected in a small number of coral samples and had a very low abundance (except marine stromatolite eubacteria in $\mathrm{Pd} 2 \_\mathrm{SjR}$ ). At the class level (Additional file 2: Fig. S1), the dominant taxa were unclassified_p_unclassified bacteria I and unclassified Proteobacteria in most coral samples from WzI, HyI, XyR, and SjR. Chlorobi was the dominant class in all coral samples from DyB (ranging from 47\% to 96\%) and P13_SjR (84\%) from SjR. In addition, unclassified_p_unclassified bacteria II was the dominant group in most coral samples from Lht (ranging from 28\% to 87\%) and Hm1_SjR from SjR (89\%). The abundance of most other classes, including Alphaproteobacteria, Betaproteobacteria, and Deltaproteobacteria, was very low. At 
177

other taxonomic levels (order, family, genus, and species), the unclassified diazotrophs were the dominant groups. These results indicated that the coral holobionts contained many diazotrophs that have not been isolated and recognized.

At the genus level, Venn diagrams showed that most diazotrophic genera were common (14 and 20 among CDSs and CDRs, respectively) in multiple sample groups (Fig. 4). Among these genera, Vibrio and Chlorobium overlapped exactly among coral reefs and coral species (Table 2). In addition to overlapping genera, there were some unique diazotrophic genera for each sample group, whether in CDSs or CDRs (Table 3). For example, Desulfobacter was endemic to coral individuals from DyB. Chroococcidiopsis appeared only in the coral species Goniastrea retiformis. Overall, 15 diazotrophic genera were endemic to different groups of CDRs, and 14 genera were endemic to different groups of CDSs. These endemic diazotrophic species were directly related to the coral host species and external environment.

\section{Environmental variables affecting the distribution of diazotrophic species}

The six sampling locations were distributed in different areas of the South China Sea. These coral reefs were affected by different environmental factors due to their geographical locations (Additional file 1:

Table S2). The concentrations of dissolved inorganic nitrogen (DIN) and other nutrients were lower in HyI, XyR, and SjR, which were far from land, than in the other locations. In contrast, these nutrient concentrations were 2 to 10 times higher in some coastal sampling locations (e.g., DyB, WzI, and Lht) than in those far from land. Turbidity (Tur) was also significantly higher in the coastal reefs than in the offshore reefs. The correlations between various environmental parameters and communities of coral-associated diazotrophs (the top 20 taxa based on total abundance at the genus level) were then evaluated (Fig. 5). The results showed that the effects of different environmental factors on bacterial 
199

200

communities were significantly different. According to similar effects, environmental factors were clustered into two groups: group I, including DIN, Tur, latitude (Lat), $\mathrm{PO}_{4}{ }^{3-}(\mathrm{SRP})$, and $\mathrm{SiO}_{3}{ }^{2-}$, and group II, including pH, dissolved oxygen (DO), longitude (Lng), temperature (Tem), and salinity (Sal). Group I correlated positively with unclassified_f_Chlorobiaceae $(0.26 \leq \mathrm{R} \leq 0.49)$, Chlorobium $(0.29 \leq$ $\mathrm{R} \leq$ 0.37), unclassified_p_unclassified Bacteria $\mathrm{II} \quad(0.30 \leq \mathrm{R} \leq 0.43)$ and unclassified_o_Desulfuromonadales $(0.25 \leq \mathrm{R} \leq 0.44)$ and negatively with four other bacterial genera, namely, unclassified_c_norank_p_Cyanobacteria $(-0.42 \leq \mathrm{R} \leq-0.24)$, norank_p_unclassified Bacteria I $(-0.37 \leq \mathrm{R} \leq-0.25)$, unclassified_c_Alphaproteobacteria $(-0.44 \leq \mathrm{R} \leq-0.30)$, and unclassified_p_Cyanobacteria $(-0.44 \leq \mathrm{R} \leq-0.30)$. The correlations of other environmental factors with a series of bacterial genera in group II were generally opposite to those in group I (Fig. 5).

\section{Discussion}

Microbial nitrogen fixation requires a nitrogenase gene, nifH, which has been confirmed to be consistent with the phylogenesis of the 16S rRNA gene [29]. Our annotation results revealed that microorganisms capable of nitrogen fixation were ubiquitously present in coral holobionts. Their presence was not related to the external environment. The six sampling locations were distributed in different areas of the South China Sea. The concentrations of DIN and other nutrients were very high in some fringing reef sampling locations (e.g., DyB, WzI, and Lht). In contrast, the concentrations of these nutrients were low in some island reefs (HyI, $\mathrm{XyR}$, and $\mathrm{SjR})$, which were far from land. The nutrients in coastal coral reefs could completely meet the nitrogen demand of coral holobionts, even without biological nitrogen fixation. However, diazotrophs and coral hosts coexist well and coevolve over the long term [30]. It can be speculated that coral-associated diazotrophs have many other biological functions in addition to nitrogen fixation, such as the coordination of carbon fixation. For 
221

222

example, Cyanobacteria is a phylum of prokaryotic microorganisms that can carry out photosynthesis with oxygen production [31]. They can also fix atmospheric nitrogen and convert it into ammonia $\left(\mathrm{NH}_{3}\right)$, nitrite $\left(\mathrm{NO}_{2}^{-}\right)$, or nitrate $\left(\mathrm{NO}_{3}^{-}\right)$, which can provide available nitrogen to other organisms [12, 32].

In this study, the most striking finding was that the fluctuations of coral-associated diazotrophic composition, which were identified via the analysis of alpha- and beta-diversity and species differences, were highly significantly different between CDRs (Fig. 1). Notably, community richness, which was reflected by the ACE, was lower for coral-associated diazotrophs from DyB and Lht than for those from WzI, HyI, SjR, and XyR (Fig. 1A). This may be attributed to the reef types of DyB and Lht, which are a kind of typical fringing reef frequently affected by human activities and contain high concentrations of nutrients and DO. The community diversity, which was reflected by the Shannon index, exhibited the same trend as the ACE for coral-associated diazotrophs from DyB and Lht (Fig. 1C). This may be related to the fact that high concentrations of nutrients (especially DIN) can meet some of the nitrogen requirements of corals. However, this finding was contrary to the results of the analysis of coral-associated bacterial diversity obtained by high-throughput sequencing based on $16 \mathrm{~S}$ rRNA gene amplification. Li et al. studied the bacterial diversity associated with Porites lutea, Galaxea fascicularis, and Acropora millepora sampled from Lht. The results showed that the ACE and Shannon index were 855.53-8970.90 and 4.16-7.04, respectively [27]. Additionally, our previous study found that the ACE and Shannon index of 25 scleractinian coral samples from XyR were 332.22-1500.66 and 1.91-5.88, respectively [28]. McKew et al. also showed that bacterial communities from Caribbean corals were significantly more diverse than those from Indonesian corals [33]. In this study, the relationships between coral-associated bacteria were structured by multiple factors at different scales. 
243 For example, the diversity and composition of bacterial communities associated with corals are

244 significantly affected by various factors, including coral species [34], geography [33], skeletal

245 morphology [28], and others [35, 36]. However, the relationship between coral-associated

246 nitrogen-fixing bacteria and other bacteria is not yet clear. In this study, the characteristics of dominant

247 coral-associated diazotrophs, which exhibited significant geographical differences, were clearly recognized. At the same time, some core diazotrophs were found in different coral reefs or coral species.

249 In addition, there were some unique diazotrophs in different coral reefs or coral species. The PCoA also showed that coral samples from different locations were clearly separated based on diazotrophic composition (Fig. 2). We speculated that the selection of coral-associated diazotrophs was directly related to coral species and their living environments. Because environmental variables were significantly different between these coral reefs, correlation analysis revealed that various environmental factors correlated positively or negatively with different bacterial genera. For example, the effects of group I (Lat, SRP, $\mathrm{SiO}_{3}{ }^{2-}, \mathrm{DIN}$, and Tur) and group II (pH, DO, Temp, Sal, and Lng) on most of the diazotrophic communities were similar. The correlations between the distribution of

257 nitrogen-fixing bacteria associated with corals and environmental factors were reported for the first time in this study. The findings of this study shed light on the communities and dominant groups of diazotrophs in characteristic coral reefs and their relationships with key environmental variables.

\section{Conclusions}

Our results fully reflected the diversity of diazotrophs associated with different coral species sampled

262 from a number of coral reefs that varied in environmental variables in the South China Sea. Although many diazotrophic species were unclassified, it was shown that the predominant taxa of diazotrophs among six different coral reefs exhibited more significant geographical differences than interspecific 
differences. In addition, the correlation analysis revealed that various environmental factors correlated positively or negatively with different bacterial genera. We think that corals tend to associate with unclassified_f_Chlorobiaceae, Chlorobium, unclassified_p_unclassified Bacteria II, and unclassified_o_Desulfuromonadales as symbiotic nitrogen-fixing bacteria under changes in nutrient enrichment. In addition, corals from high-latitude reefs may tend to associate with unclassified_c_norank_p_Cyanobacteria, norank_p_unclassified Bacteria unclassified_c_Alphaproteobacteria, and unclassified_p_Cyanobacteria under global warming. An understanding of diazotrophic communities associated with scleractinian corals from reefs with significantly different environmental characteristics in the South China Sea will help us anticipate possible changes in coral reefs in response to future environmental changes.

\section{Materials and methods}

\section{Study sites, coral sample collection, and species identification}

In this study, 6 locations in the South China Sea, namely, DyB, WzI, Lht, HyI, SjR, and XyR, were selected (Fig. 6). Coral samples were collected using a hammer and chisel by way of scuba diving at a depth of 5-8 $\mathrm{m}$ from a specific site in each selected location (Table 4). Three replicate samples (approximately $6 \times 6 \mathrm{~cm}$ ) were collected from the sides of the colonies. The distance between two colonies of the same reef was greater than 10 meters. Some widely distributed coral species, such as $P$. lutea and G. retiformis, needed to be collected as much as possible from different coral reefs where they grow. The collected samples were washed with sterile seawater 3 times and then placed in sterile plastic bags. All samples were briefly stored at low temperatures $\left(0-4^{\circ} \mathrm{C}\right)$ and then immediately transported back to the laboratory for DNA extraction.

A total of 68 coral samples, which included 6 families, 9 genera, and 11 species (Table 4), were 
identified and selected as the study subjects according to their ecological and morphological characteristics.

\section{Seawater collection, nutrition, and environmental factor detection}

Three to five liters of seawater was collected at a depth of 5-8 $\mathrm{m}$ using a water sampler around each site. The distance between two sampling sites was not less than 100 meters. The Temp, Sal, Tur, and pH values were immediately measured on site using a thermometer, salinometer, turbidimeter, and acidometer, respectively. Pore water was extracted from sediments by centrifugation (3,500 rpm, 40 $\min$ ), filtered through 0.45 - $\mu \mathrm{m}$-pore-size cellulose acetate filters, and then collected in acid-precleaned vials. Finally, all samples were stored in an icebox for transport to the laboratory and stored in deep freezers until analyses [37]. All nutrient statuses, including the concentrations of DIN $\left(\mathrm{DIN}=\mathrm{NH}_{4}^{+}+\right.$ $\mathrm{NO}_{2}^{-}+\mathrm{NO}_{3}^{-}$), $\mathrm{PO}_{4}^{3-}$, and $\mathrm{SiO}_{3}^{2-}$, were measured according to "Specifications for oceanographic survey" (General Administration of Quality Supervision, Inspection and Quarantine of the People's Republic of China, 1991) [37]. The average physical and chemical parameters from at least three samples of each coral reef were tested. Lng and Lat were detected by global positioning system (GPS).

\section{DNA extraction, PCR amplification and Illumina MiSeq sequencing}

Small pieces of coral samples, including tissue, mucus and skeleton (approximately $50 \mathrm{mg}$ ), were cut with a pair of scissors and used for genomic DNA extraction with the TIANamp Marine Animals DNA Kit (Tiangen Biotech (Beijing) Co., Ltd., Beijing, China) according to the manufacturer's instructions. The nitrogen-fixing gene ( $n$ ifH) of diazotrophs was amplified using the specific forward primer nifH-F (5'-AAAGGYGGWATCGGYAARTCCACCAC-3') and reverse primer nifH-R (5'-TTGTTSGCSGCRTACATSGCCATCAT-3'), where the barcode was an eight-base sequence unique to each sample [38-41]. The reaction system and procedure for PCR using an ABI GeneAmp® 9700 
thermal cycler and TransGen AP221-02 PCR kit (TransStart FastPfu DNA Polymerase, $20 \mu 1$ reaction system) were the same as those described in a previous report [42]. The following steps were employed in the PCR: a 3-minute hot start at $95^{\circ} \mathrm{C}$ after the reaction system was configured according to the manufacturer's instructions; 35 cycles of denaturation at $95^{\circ} \mathrm{C}$ for 30 seconds, annealing at $57^{\circ} \mathrm{C}$ for 30 seconds, and elongation at $72^{\circ} \mathrm{C}$ for 45 seconds; an extension at $72^{\circ} \mathrm{C}$ for 10 minutes; and preservation at $10^{\circ} \mathrm{C}$ until halted by the user. Triplicate PCR products were pooled for each sample, and fragments with size ranges of $421-440 \mathrm{bp}$ were then purified and quantified using an AxyPrep DNA gel extraction kit (Axygen Biosciences, Union City, CA, U.S.A.) and QuantiFluor ${ }^{\mathrm{TM}}-\mathrm{ST}$ fluorometer (Promega, U.S.A.). Purified amplicons were pooled in equimolar amounts and paired-end sequenced (2 $\times 250 \mathrm{bp}$ ) on the Illumina MiSeq platform according to standard protocols (Majorbio Bio-Pharm Technology Co. Ltd., Shanghai, China).

\section{Data analysis}

Raw sequences were optimized using Trimmomatic to exclude reads with homopolymer inserts and low-quality scores $(<20)$ [43]. The obtained high-quality reads with more than $10 \mathrm{bp}$ of overlapping sequence were merged by FLASH software [44]. The merged sequences were clustered into OTUs with a 97\% similarity cutoff using UPARSE software (version $7.1 \mathrm{http} / /$ drive5.com/uparse/) and were then identified, and all chimeric sequences were removed using UCHIME software [45]. The obtained sequences were finally used for taxonomic analysis. The taxonomy of representative sequences from the most abundant sequences within each OTU was analyzed by the RDP Classifier algorithm (http://rdp.cme.msu.edu/) against the fgr/nifH database (release 7.3, http://fungene.cme.msu.edu/nifH), setting a confidence threshold of $70 \%$ [45]. The indices of community richness (ACE) [46] and community diversity (Shannon) $[47,48]$ were estimated for each sample by extracting the same 
331

332

333

numbers of reads (10,000 valid sequences) using mothur (version v.1.30.1) [49]. The taxonomy was assigned and compared with that in the fgr/nifH database [50] using the QIIME platform (http://qiime.org/scripts/assign_taxonomy.html). Moreover, similarities or differences in the composition of bacterial communities were reflected by PCoA using Bray-Curtis distances at the OTU level [51]. A heatmap of the correlations between environmental variables and nitrogen-fixing bacteria associated with corals was constructed by Spearman's correlation test and GraphPad Prism version 6.00 (GraphPad Software, San Diego, CA, USA). Significance was assigned at $P<0.05\left(^{*}\right)$.

\section{Supplementary information}

Additional file 1: Additional tables.

Additional file 2: Fig. S1. Composition profiles of diazotrophs. Taxonomic classification of bacterial reads retrieved from all the coral samples at the class level using RDP Classifier; "others" represents the bacteria with an abundance less than $0.1 \%$.

\section{Acknowledgments}

We thank all the assistants who collected samples and data during this study.

\section{Author contributions}

KY and JL conceived the research; YW, $\mathrm{XH}, \mathrm{WH}$, and ZW contributed the materials; JL performed all experiments; ZQ and GW constructed all figures; BC and HS identified coral species; JL and KY wrote the manuscript; and all authors edited and approved the manuscript.

\section{Funding}

This work was funded by the National Natural Science Foundation of China (91428203 and 41666005), 
351

352

353

354

355

356

357

358

359

360

361

362

363

364

Science and Technology Project of Guangxi (Nos. AD17129063 and AA17204074), BaGui Scholars

Program Foundation (2014BGXZGX03) and the Basic Ability Promotion Project for Young and

Middle-aged Teachers in Universities of Guangxi (2017KY0021).

\section{Availability of data and materials}

The datasets analyzed during the current study are available from the [NCBI Sequence Read Archive]

repository under accession number

SRP145254

[https://www.ncbi.nlm.nih.gov/search/all/?term=SRP145254].

\section{Ethical approval and consent to participate}

Permits for coral sampling were provided by the State Oceanic Administration, People's Republic of

China, and the local Department of Ocean and Fisheries.

\section{Consent for publication}

Not applicable.

\section{Competing interests}

The authors declare that they have no competing interests.

\section{Author details}

${ }^{1}$ Coral Reef Research Center of China, Guangxi University, Nanning 530004, China. ${ }^{2}$ Guangxi

Laboratory on the Study of Coral Reefs in the South China Sea, Nanning 530004, China. ${ }^{3}$ School of

Marine Sciences, Guangxi University, Nanning 530004, China. ${ }^{4}$ State Key Laboratory of Tropical

Oceanography (LTO), South China Sea Institute of Oceanology, Chinese Academy of Sciences,

Guangzhou 510301, China. 


\section{References}

1. Connell JH. Diversity in tropical rain forests and coral reefs. Science. 1978;199(4335):1302-1310.

2. Nakajima R, Tsuchiya K, Nakatomi N, Yoshida T, Tada Y, Konno F, Toda T, Kuwahara VS, Hamasaki K, Othman BHR et al. Enrichment of microbial abundance in the sea-surface microlayer over a coral reef: Implications for biogeochemical cycles in reef ecosystems. Mar Ecol Prog Ser. 2013;490:11-22.

3. Rädecker N, Pogoreutz C, Voolstra CR, Wiedenmann J, Wild C. Nitrogen cycling in corals: The key to understanding holobiont functioning? Trends Microbiol. 2015;23(8):490-497.

4. Muscatine L, Falkowski PG, Dubinsky Z, Cook PA, McCloskey LR. The effect of external nutrient resources on the population dynamics of Zooxanthellae in a reef coral. Proc R Soc Lond B: Biol Sci. 1989;236(1284):311-324.

5. Olson ND, Ainsworth TD, Gates RD, Takabayashi M. Diazotrophic bacteria associated with Hawaiian Montipora corals: Diversity and abundance in correlation with symbiotic dinoflagellates J Exp Mar Biol Ecol. 2009;371(2):140-146.

6. Piniak GA, Lipschultz F, Mcclelland J. Assimilation and partitioning of prey nitrogn within two anthozoans and their endosymbiotic zooxanthellae. Mar Ecol Prog. 2003;262(262):125-136.

7. Crossland CJ, Barnes DJ. Acetylene reduction by coral skeletons. Limnol Oceanogr. 1976;21(1):153-156.

8. Davey M, Holmes G, Johnstone R. High rates of nitrogen fixation (acetylene reduction) on coral skeletons following bleaching mortality. Coral Reefs. 2008;27(1):227-236.

9. Chimetto LA, Brocchi M, Thompson CC, Martins RCR, Ramos HR, Thompson FL. Vibrios dominate as culturable nitrogen-fixing bacteria of the Brazilian coral Mussismilia hispida. Syst Appl Microbiol. 2008;31(4):312-319.

10. Wegley L, Edwards R, Rodriguez-Brito B, Liu H, Rohwer F. Metagenomic analysis of the microbial community associated with the coral Porites astreoides. Environ Microbiol. 2007;9(11):2707-2719.

11. Lema KA, Willis BL, Bourne DG. Corals form characteristic associations with symbiotic nitrogen-fixing bacteria. Appl Environ Microbiol. 2012;78(9):3136-3144.

12. Lesser MP, Mazel CH, Gorbunov MY, Falkowski PG. Discovery of symbiotic nitrogen-fixing cyanobacteria in corals. Science. 2004;305(5686):997-1000.

13. Yang SH, Lee STM, Huang CR, Tseng CH, Chiang PW, Chen CP, Chen HJ, Tang SL. Prevalence of potential nitrogen-fixing, green sulfur bacteria in the skeleton of reef-building coral Isopora palifera. Limnol Oceanogr. 2016;61(3).

14. Wilkinson CR, Williams DM, Sammarco PW, Hogg RW, Trott LA. Rates of nitrogen fixation on coral reefs across the continental shelf of the central Great Barrier Reef. Mar Biol. 1984;80(3):255-262.

15. Williams WM, Viner AB, Broughton WJ. Nitrogen fixation (acetylene reduction) associated with the living coral Acropora variabilis. Mar Biol. 1987;94(4):531-535.

16. Cardini U, Van Hoytema N, Bednarz VN, Rix L, Foster RA, Al-Rshaidat MMD, Wild C. Microbial dinitrogen fixation in coral holobionts exposed to thermal stress and bleaching. Environ Microbiol. 2016;18(8):2620-2633. 
17. Rougerie F, Wauthy B. The endo-upwelling concept: from geothermal convection to reef construction. Coral Reefs. 1993;12(1):19-30.

18. Sammarco P, Risk M, Schwarcz H, Heikoop J. Cross-continental shelf trends in coral $\partial 15 \mathrm{~N}$ on the Great Barrier Reef: further consideration of the reef nutrient paradox. Mar Ecol Prog. 1999;180(1):131-138.

19. Sarhan T, Vargas M, Vargas JM, Plaza F. Upwelling mechanisms in the northwestern Alboran Sea. J Mar Syst. 2000;23(4):317-331.

20. Yamamuro M, Kayanne H, Minagawa M. Carbon and nitrogen stable isotopes of primary producers in coral reef ecosystems. Limnol Oceanogr. 1995;40(3):617-621.

21. Grover R, Ferrier-Pagès C, Maguer JF, Ezzat L, Fine M. Nitrogen fixation in the mucus of Red Sea corals. J Exp Biol. 2014;217(Pt 22):3962.

22. Lema KA, Clode PL, Kilburn MR, Thornton R, Willis BL, Bourne DG. Imaging the uptake of nitrogen-fixing bacteria into larvae of the coral Acropora millepora. ISME J. 2015;10(7).

23. Lema KA, Willis BL, Bourne DG. Corals form characteristic associations with symbiotic nitrogen-fixing bacteria. Appl Environ Microb. 2012;78(9):3136.

24. Yu KF, Zhao JX, Liu TS, Wei GJ, Wang PX, Collerson KD. High-frequency winter cooling and reef coral mortality during the Holocene climatic optimum. Earth Planet Sc Lett. 2004;224(1):143-155.

25. Yu KF. Coral reefs in the South China Sea: Their response to and records on past environmental changes. Sci China Earth Sci. 2012;55(8):1217-1229.

26. Zhang R, Yu K, Li A, Wang Y, Huang X. Antibiotics in corals of the South China Sea: Occurrence, distribution, bioaccumulation, and considerable role of coral mucus. Environ pollut. 2019;250:503-510.

27. Li J, Chen Q, Zhang S, Huang H, Yang J, Tian XP, Long LJ. Highly heterogeneous bacterial communities associated with the South China Sea reef corals Porites lutea, Galaxea fascicularis and Acropora millepora. Plos One. 2013;8(8):e71301.

28. Liang J, Yu K, Wang Y, Huang X, Huang W, Qin Z, Pan Z, Yao Q, Wang W, Wu Z. Distinct bacterial communities associated with massive and branching scleractinian corals and potential linkages to coral susceptibility to thermal or cold stress. Front Microbiol. 2017;8:1-10.

29. Zehr JP, Jenkins BD, Short SM, Steward GF. Nitrogenase gene diversity and microbial community structure: a cross-system comparison. Environ Microb. 2003;5(7):539-554.

30. Lema KA, Bourne DG, Willis BL. Onset and establishment of diazotrophs and other bacterial associates in the early life history stages of the coral Acropora millepora. Mol Ecol. 2015;23(19):4682-4695.

31. Hamilton TL, Bryant DA, Macalady JL. The role of biology in planetary evolution: cyanobacterial primary production in low-oxygen Proterozoic oceans. Environ Microb. 2015;18(2):325-340.

32. Charpy L, Palinska KA, Casareto B, Langlade MJ, Suzuki Y, Abed RM, Golubic S. Dinitrogen-fixing cyanobacteria in microbial mats of two shallow coral reef ecosystems. Microb Ecol. 2010;59(1):174.

33. Mckew BA, Dumbrell AJ, Daud SD, Hepburn L, Thorpe E, Mogensen L, Whitby C. Characterization of geographically distinct bacterial communities associated with coral mucus produced by Acropora spp. and Porites spp. Appl Environ Microbiol. 2012;78(15):5229-5237.

34. Hong MJ, Yu YT, Chen CA, Chiang PW, Tang SL. Influence of species specificity and other factors on bacteria associated with the coral Stylophora pistillata in Taiwan. Appl Environ 
Microbiol. 2009;75(24):7797.

35. Bourne D, Iida Y, Uthicke S, Smith-Keune C. Changes in coral-associated microbial communities during a bleaching event. ISME J. 2008;2(4):350-363.

36. Ceh J, Raina JB, Soo RM, Van KM, Bourne DG. Coral-bacterial communities before and after a coral mass spawning event on Ningaloo Reef. Plos One. 2012;7(5):e36920.

37. Guo J, Yu K, Wang Y, Xu D, Huang X, Zhao M, Yang H, Zhang R. Nutrient distribution in coral reef degraded areas within Sanya Bay, South China Sea. J Coastal Res. 2017;335:1148-1160.

38. Rösch C, Mergel A, Bothe H. Biodiversity of denitrifying and dinitrogen-fixing bacteria in an acid forest soil. Appl Environ Microbiol. 2002;68(8):3818-3829.

39. Mori H, Maruyama F, Kato H, Toyoda A, Dozono A, Ohtsubo Y, Nagata Y, Fujiyama A, Tsuda M, Kurokawa K. Design and experimental application of a novel non-degenerate universal primer set that amplifies prokaryotic 16S rRNA genes with a low possibility to amplify eukaryotic rRNA genes. DNA Res. 2014;21(2):217-227.

40. Xu N, Tan G, Wang H, Gai X. Effect of biochar additions to soil on nitrogen leaching, microbial biomass and bacterial community structure. Eur J Soil Biol. 2016;74:1-8.

41. Hamady M, Walker JJ, Harris JK, Gold NJ, Knight R. Error-correcting barcoded primers for pyrosequencing hundreds of samples in multiplex. Nat Methods. 2008;5(3):235-237.

42. Sun Z, Li G, Wang C, Jing Y, Zhu Y, Zhang S, Liu Y. Community dynamics of prokaryotic and eukaryotic microbes in an estuary reservoir. Sci Rep. 2014;4:6966.

43. Bolger AM, Lohse M, Usadel B. Trimmomatic: a flexible trimmer for Illumina sequence data. Bioinformatics. 2014;30(15):2114-2120.

44. Magoč T, Salzberg SL. FLASH: Fast length adjustment of short reads to improve genome assemblies. Bioinformatics. 2011;27(21):2957-2963.

45. Edgar RC. Search and clustering orders of magnitude faster than BLAST. Bioinformatics. 2010;26(19):2460.

46. Qian H, Lu H, Ding H, Lavoie M, Li Y, Liu W, Fu Z. Analyzing Arabidopsis thaliana root proteome provides insights into the molecular bases of enantioselective imazethapyr toxicity. Sci Rep. 2015;5:11975.

47. Allen B, Kon M, Bar-Yam Y. A new phylogenetic diversity measure generalizing the shannon index and its application to phyllostomid bats. Am Nat. 2009;174(2):236-243.

48. Zhang Y. Relations between Shannon entropy and genome order index in segmenting DNA sequences. Phys Rev E Stat Nonlin Soft Matter Phys. 2009;79(4 Pt 1):041918.

49. Schloss PD, Gevers D, Westcott SL. Reducing the effects of PCR amplification and sequencing artifacts on 16S rRNA-based studies. Plos One. 2011;6(12):e27310.

50. Quast C, Pruesse E, Yilmaz P, Gerken J, Schweer T, Yarza P, Peplies J, Glöckner FO. The SILVA ribosomal RNA gene database project: improved data processing and web-based tools. Nucleic Acids Res. 2013;41(Database issue):590-596.

51. Lozupone C, Knight R. UniFrac: a new phylogenetic method for comparing microbial communities. Appl Environ Microbiol. 2005;71(12):8228-8235. 
Table 1 Number of diazotrophs associated with different coral colonies at different taxonomic levels.

\begin{tabular}{|c|c|c|c|c|c|c|c|}
\hline Coral code & Phylum & Class & Order & Family & Genus & Species & OTU \\
\hline Gr3_HyI & 5 & 9 & 11 & 11 & 12 & 12 & 68 \\
\hline Pv1_Lht & 4 & 8 & 10 & 10 & 10 & 11 & 64 \\
\hline Pv3_HyI & 5 & 10 & 14 & 16 & 17 & 17 & 202 \\
\hline Pl4_HyI & 6 & 11 & 16 & 18 & 19 & 19 & 179 \\
\hline Pv2_WzI & 5 & 8 & 10 & 10 & 10 & 10 & 34 \\
\hline Pcl_SjR & 5 & 10 & 15 & 16 & 16 & 16 & 146 \\
\hline Gr2_XyR & 5 & 10 & 12 & 13 & 15 & 15 & 130 \\
\hline Pv3_Lht & 3 & 4 & 5 & 5 & 5 & 5 & 21 \\
\hline Gf2_DyB & 5 & 10 & 16 & 16 & 17 & 17 & 143 \\
\hline Pv3_WzI & 3 & 7 & 9 & 9 & 9 & 9 & 103 \\
\hline Pl1_XyR & 5 & 6 & 7 & 9 & 11 & 11 & 74 \\
\hline Pd2_DyB & 5 & 8 & 10 & 11 & 12 & 12 & 88 \\
\hline Pl4_WzI & 7 & 10 & 14 & 16 & 17 & 17 & 215 \\
\hline Hm1_DyB & 4 & 7 & 8 & 8 & 10 & 10 & 50 \\
\hline Gr4_XyR & 4 & 9 & 14 & 14 & 15 & 15 & 66 \\
\hline Gr1_DyB & 6 & 9 & 13 & 13 & 14 & 14 & 52 \\
\hline Pl3_XyR & 4 & 9 & 12 & 12 & 12 & 12 & 153 \\
\hline Pc3_SjR & 5 & 8 & 9 & 10 & 11 & 11 & 132 \\
\hline Fp1_SjR & 3 & 7 & 9 & 9 & 9 & 9 & 96 \\
\hline Pl3_WzI & 4 & 7 & 8 & 8 & 8 & 9 & 88 \\
\hline Mel_SjR & 4 & 9 & 11 & 12 & 12 & 12 & 101 \\
\hline Gr1_XyR & 5 & 9 & 11 & 11 & 11 & 11 & 50 \\
\hline Gr3_XyR & 6 & 11 & 18 & 19 & 21 & 21 & 280 \\
\hline Pl2_WzI & 4 & 8 & 16 & 16 & 17 & 17 & 117 \\
\hline Fp1_XyR & 5 & 9 & 11 & 13 & 13 & 13 & 112 \\
\hline Fp1_WzI & 6 & 9 & 14 & 15 & 18 & 18 & 93 \\
\hline Pl1_WzI & 7 & 11 & 22 & 25 & 28 & 30 & 205 \\
\hline P14_XyR & 4 & 9 & 14 & 15 & 16 & 16 & 52 \\
\hline Pv1_WzI & 5 & 9 & 12 & 12 & 12 & 12 & 75 \\
\hline Pd1_DyB & 4 & 5 & 6 & 6 & 7 & 7 & 32 \\
\hline Pc2_HyI & 3 & 4 & 7 & 7 & 8 & 8 & 61 \\
\hline Pl3_Lht & 4 & 6 & 6 & 6 & 6 & 6 & 24 \\
\hline Pd1_SjR & 5 & 8 & 11 & 11 & 12 & 12 & 67 \\
\hline Pv2_HyI & 6 & 9 & 13 & 13 & 13 & 13 & 62 \\
\hline Gr1_HyI & 4 & 6 & 9 & 11 & 11 & 11 & 80 \\
\hline Hm2_SjR & 5 & 8 & 9 & 9 & 10 & 10 & 33 \\
\hline
\end{tabular}




\begin{tabular}{|c|c|c|c|c|c|c|c|}
\hline Pv1_HyI & 5 & 9 & 12 & 13 & 13 & 13 & 179 \\
\hline Hm1_SjR & 7 & 9 & 11 & 11 & 11 & 11 & 54 \\
\hline Gf1_DyB & 5 & 6 & 7 & 7 & 8 & 8 & 55 \\
\hline P11_SjR & 4 & 5 & 6 & 6 & 6 & 6 & 30 \\
\hline Pl5_HyI & 7 & 12 & 19 & 20 & 21 & 21 & 144 \\
\hline Pc1_HyI & 6 & 10 & 16 & 19 & 20 & 21 & 154 \\
\hline Gr2_DyB & 5 & 10 & 11 & 11 & 12 & 12 & 86 \\
\hline Gr5_XyR & 4 & 9 & 14 & 15 & 15 & 15 & 125 \\
\hline Fp1_Lht & 5 & 8 & 9 & 9 & 10 & 10 & 49 \\
\hline Pd2_SjR & 7 & 12 & 16 & 16 & 17 & 17 & 121 \\
\hline Pl4_SjR & 6 & 10 & 14 & 14 & 15 & 15 & 69 \\
\hline Gr4_DyB & 5 & 8 & 10 & 10 & 11 & 11 & 96 \\
\hline Pc2_SjR & 3 & 7 & 11 & 12 & 12 & 12 & 104 \\
\hline P14_Lht & 3 & 4 & 5 & 5 & 5 & 5 & 37 \\
\hline Fp3_WzI & 5 & 9 & 16 & 19 & 21 & 23 & 291 \\
\hline $\mathrm{Me} 2 \_\mathrm{SjR}$ & 4 & 8 & 11 & 12 & 12 & 12 & 57 \\
\hline Ar2_XyR & 6 & 8 & 11 & 12 & 14 & 14 & 111 \\
\hline Ar1_XyR & 6 & 11 & 17 & 18 & 18 & 18 & 136 \\
\hline Pl3_HyI & 6 & 9 & 12 & 12 & 12 & 12 & 36 \\
\hline Pl2_SjR & 4 & 6 & 7 & 7 & 7 & 7 & 31 \\
\hline Ar3_XyR & 7 & 10 & 11 & 14 & 14 & 14 & 189 \\
\hline Pl2_HyI & 4 & 7 & 10 & 11 & 11 & 11 & 62 \\
\hline Gr3_DyB & 5 & 7 & 7 & 7 & 8 & 8 & 30 \\
\hline Pl3_SjR & 3 & 6 & 7 & 7 & 7 & 7 & 34 \\
\hline Gr2_HyI & 5 & 10 & 15 & 16 & 17 & 17 & 143 \\
\hline Pl2_Lht & 5 & 10 & 15 & 16 & 17 & 18 & 199 \\
\hline P11_Lht & 6 & 9 & 12 & 14 & 15 & 16 & 77 \\
\hline Pe1_SjR & 7 & 11 & 16 & 16 & 16 & 16 & 133 \\
\hline Fp2_WzI & 6 & 10 & 14 & 14 & 14 & 14 & 200 \\
\hline Pv2_Lht & 6 & 9 & 10 & 11 & 12 & 13 & 52 \\
\hline Pl1_HyI & 6 & 11 & 15 & 18 & 19 & 19 & 121 \\
\hline Pl2_XyR & 5 & 8 & 10 & 10 & 10 & 10 & 51 \\
\hline
\end{tabular}


511 Table 2 Overlapping diazotrophic genera associated with different coral sample groups.

\section{Bacterial genera in different coral reefs ${ }^{a}$}

[DyB $(\mathrm{n}=9, \mathrm{~m}=4), \mathrm{WzI}(\mathrm{n}=10, \mathrm{~m}=3), \operatorname{Lht}(\mathrm{n}=8, \mathrm{~m}=8)$, HyI $(\mathrm{n}=13, \mathrm{~m}=4), \mathrm{SjR}(\mathrm{n}=15, \mathrm{~m}=7)$, and XyR $(\mathrm{n}=13, \mathrm{~m}$ $=4)]$

g_unclassified_f_Chlorobiaceae

g_Teredinibacter

g_Vibrio

g_norank_c_unclassified_Cyanobacteria

g_unclassified_c_Alphaproteobacteria

g_unclassified_c_norank_p_Cyanobacteria

g_unclassified_k_norank_d_Bacteria

g_unclassified_p_Cyanobacteria

g_unclassified_o_Rhizobiales

g_unclassified_p_Proteobacteria

g_unclassified_c_Gammaproteobacteria

g_unclassified_p_unclassified Bacteria II

\section{g_Chlorobium}

g_unclassified_c_Deltaproteobacteria
Bacterial genera in different coral species

[Pl (n=21), Pv (n=9), Gr (n=12), Fp $(n=6)$, and Pc $(n=5)]$

g_unclassified_o_Rhizobiales

g_Vibrio

g_unclassified_o_Desulfuromonadales

g_norank_c_unclassified_Cyanobacteria

g_unclassified_c_Alphaproteobacteria

g_unclassified_c_norank_p_Cyanobacteria

g_unclassified_k_norank_d_Bacteria

g_unclassified_o_Chroococcales

g_Desulfuromonas

g_Mastigocoleus

g_unclassified_f_Chromatiaceae

g_unclassified_p_Cyanobacteria

g__unclassified_f__Chlorobiaceae

g_unclassified_o_Chromatiales

g_unclassified_p_Proteobacteria

g_unclassified_c_Gammaproteobacteria

g_unclassified_p_unclassified Bacteria II

g_Bradyrhizobium

g_Chlorobium

g_unclassified_c_Deltaproteobacteria

$512 \mathrm{n}=$ number of coral individuals, $\mathrm{m}=$ number of coral species. ${ }^{\mathrm{a}}$ Different coral reefs are represented by

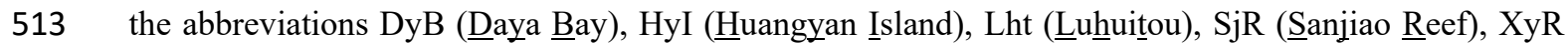

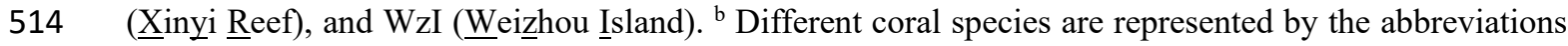


516 (Plesiastrea. curta). The red-labeled bacteria are the species with exact overlap between coral reefs or

517 coral species.

518

519

520

521

522

523

524

525

526

527

528

529

530

531

532

533

534

535

536

537

538

539

540

541

542

543

544

545

546

547

548

549

550

551

552

553

554

555

556

557 
Table 3 Endemic diazotrophic genera from different sample groups.

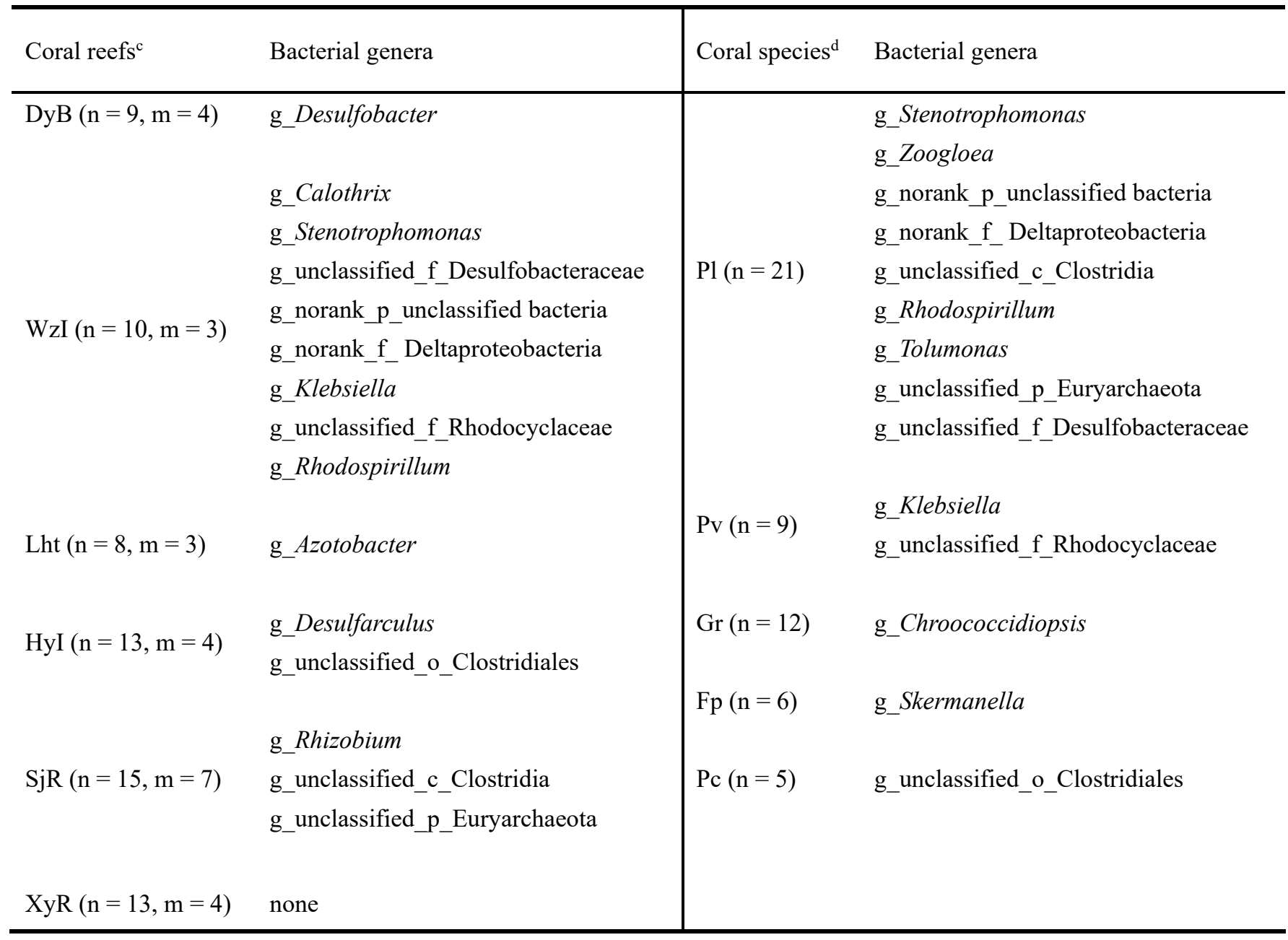

559 The indications for $\mathrm{n}, \mathrm{m},{ }^{\mathrm{c}}$, and ${ }^{\mathrm{d}}$ are consistent with those in Table 2. 
Table 4 The locations, coral species, and number of sampled corals.

\begin{tabular}{|c|c|c|c|c|}
\hline $\begin{array}{l}\text { Site location } \\
\text { (Longitude, Latitude) }\end{array}$ & Sampling date & Coral species & Coral code ${ }^{\#}$ & $\begin{array}{l}\text { Colony } \\
\text { number }\end{array}$ \\
\hline \multirow{4}{*}{$\begin{array}{l}\text { Daya Bay } \\
\left(114^{\circ} 38^{\prime} 40^{\prime \prime} \mathrm{E}, 22^{\circ} 34^{\prime} 57^{\prime \prime} \mathrm{N}\right)\end{array}$} & \multirow{4}{*}{01 September 2015} & Galaxea fascicularis & Gf1_DyB, Gf2_DyB & 2 \\
\hline & & Goniastrea retiformis & $\begin{array}{l}\text { Gr1_DyB, Gr2_DyB, Gr3_DyB, } \\
\text { Gr4_DyB }\end{array}$ & 4 \\
\hline & & Pavona decussata & Pd1_DyB, Pd2_DyB & 2 \\
\hline & & Hydnophora microconos & Hm1_DyB & 1 \\
\hline \multirow{3}{*}{$\begin{array}{l}\text { Weizhou Island } \\
\left(109^{\circ} 06^{\prime} 40^{\prime \prime} \mathrm{E}, 21^{\circ} 04^{\prime} 30^{\prime \prime} \mathrm{N}\right)\end{array}$} & \multirow{3}{*}{23 October 2015} & Porites lutea & $\begin{array}{l}\text { Pl1_WzI, P12_WzI, Pl3_WzI, } \\
\text { Pl4_WzI }\end{array}$ & 4 \\
\hline & & Favia palauensis & Fp1_WzI, Fp2_WzI, Fp3_WzI & 3 \\
\hline & & Plesiastrea versipora & Pv1_WzI, Pv2_WzI, Pv3_WzI & 3 \\
\hline \multirow{3}{*}{$\begin{array}{l}\text { Luhuitou } \\
\left(109^{\circ} 29^{\prime} 16^{\prime \prime} \mathrm{E}, 18^{\circ} 13^{\prime} 18^{\prime \prime} \mathrm{N}\right)\end{array}$} & \multirow{3}{*}{15 October 2016} & Porites lutea & $\begin{array}{l}\text { Pl1_Lht, P12_Lht, Pl3_Lht, } \\
\text { P14_Lht }\end{array}$ & 4 \\
\hline & & Plesiastrea versipora & Pv1_Lht, Pv2_Lht, Pv3_Lht & 3 \\
\hline & & Favia palauensis & Fp1_Lht & 1 \\
\hline \multirow{4}{*}{$\begin{array}{l}\text { Huangyan Island } \\
\left(117^{\circ} 44^{\prime} 49^{\prime \prime} \mathrm{E}, 15^{\circ} 13^{\prime} 08^{\prime \prime} \mathrm{N}\right)\end{array}$} & \multirow{4}{*}{15 July 2015} & Porites lutea & $\begin{array}{l}\text { P11_HyI, Pl2_HyI, Pl3_HyI, } \\
\text { Pl4_HyI, Pl5_HyI }\end{array}$ & 5 \\
\hline & & Goniastrea retiformis & Gr1_HyI, Gr2_HyI, Gr3_HyI & 3 \\
\hline & & Plesiastrea versipora & Pv1_HyI, Pv2_HyI, Pv3_HyI & 3 \\
\hline & & Plesiastrea curta & Pc1_HyI, Pc2_HyI & 2 \\
\hline \multirow{7}{*}{$\begin{array}{l}\text { Sanjiao Reef } \\
\left(115^{\circ} 12^{\prime} 41^{\prime \prime} \mathrm{E}, 10^{\circ} 13^{\prime} 24^{\prime \prime} \mathrm{N}\right)\end{array}$} & \multirow{7}{*}{19 May 2015} & Porites lutea & $\begin{array}{l}\text { Pl1_SjR, P12_SjR, Pl3_SjR, } \\
\text { Pl4_SjR }\end{array}$ & 4 \\
\hline & & Montipora efflorescens & Me1_SjR, Me2_SjR & 2 \\
\hline & & Pavona decussata & Pd1_SjR, Pd2_SjR & 2 \\
\hline & & Hydnophora microconos & Hm1_SjR, Hm2_SjR & 2 \\
\hline & & Pocillopora eydouxi & Pe1_SjR & 1 \\
\hline & & Favia palauensis & Fp1_SjR & 1 \\
\hline & & Plesiastrea curta & Pc1_SjR, Pc2_SjR, Pc3_SjR & 3 \\
\hline \multirow{4}{*}{$\begin{array}{l}\text { Xinyi Reef } \\
\left(115^{\circ} 55^{\prime} 49^{\prime \prime} \mathrm{E}, 9^{\circ} 20^{\prime} 06^{\prime \prime} \mathrm{N}\right)\end{array}$} & \multirow{4}{*}{21 May 2016} & Porites lutea & $\begin{array}{l}\text { P11_XyR, P12_XyR, P13_XyR, } \\
\text { P14_XyR }\end{array}$ & 4 \\
\hline & & Goniastrea retiformis & $\begin{array}{l}\text { Gr1_XyR, Gr2_XyR, Gr3_XyR, } \\
\text { Gr4_XyR, Gr5_XyR }\end{array}$ & 5 \\
\hline & & Acropora rosaria & Ar1_XyR, Ar2_XyR, Ar3_XyR & 3 \\
\hline & & Favia palauensis & Fp1_XyR & 1 \\
\hline
\end{tabular}

578 \# The letters before the underscore are the initials of the coral genus and species, which represent the

579 species of corals. The numbers indicate the order of coral individuals. The letters after the underscore 
580

581

582

583

584

585

586

587

588

589

590

591

592

593

594

595

596

597

598

599

600

601

602

603

604

605

606

607

608

609

610

611

612

613

614

615

616

617

618

619

620

621

622 represent the abbreviations of coral reef locations.

(n)

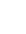




\section{Figure captions}

624 Fig. 1 Test for differences in alpha-diversity indices of coral-associated diazotrophs between sample

625 groups at the OTU level. (A) ACE between coral reefs, (B) ACE between coral species, (C) Shannon

626 index between coral reefs, and (D) Shannon index between coral species. The test used was Student's

627 t-test. The black square $(\boldsymbol{\square})$ shows the average. $\mathrm{n}=$ number of coral individuals, $\mathrm{m}=$ number of coral

628 species. Different coral reefs are represented in (A) and (C) by the abbreviations DyB (Daya Bay), HyI

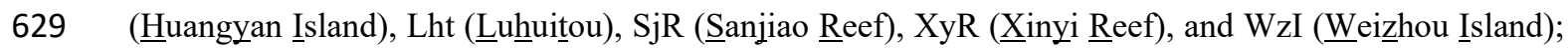

630 different coral species in (B) and (D) are represented by the abbreviations Pl (Porites lutea), Pv

(Plesiastrea versipora), Fp (Favia palauensis), Gr (Goniastrea retiformis), and Pc (Plesiastrea curta).

Fig. 2 PCoA plot at the OTU level of all the coral samples collected from six different coral reefs.

637 Abbreviations are the same as in Fig. 1.

Fig. 3 Composition profiles of diazotrophs. Taxonomic classification of bacterial reads retrieved from all the coral samples at the phylum level using RDP Classifier. (A) and coral species (B). Abbreviations are the same as in Fig. 1. 
645 Fig. 5 Correlation analyses between environmental parameters and populations of diazotrophs at the

646 genus level. The diazotrophs analyzed were the top 20 genera in terms of total abundance. Hierarchical

647 clustering of environmental variables was performed based on the raw data, while diazotrophic species

648 were clustered based on averages. Significant differences are indicated by different numbers of

649 asterisks $(0.01<p \leq 0.05 *, 0.001<p \leq 0.01 * *, p \leq 0.001 * * *)$. Nonsignificant correlations do not

650 have an asterisk. The $\mathrm{R}$ value represents the correlation coefficient, and the closer it is to 1 , the more

651 significant the correlation is. Some of the environmental variables are represented by abbreviations,

652 including Lat (latitude), $\mathrm{SRP}\left(\mathrm{PO}_{4}{ }^{3-}\right), \mathrm{SiO} 3\left(\mathrm{SiO}_{3}{ }^{2-}\right), \mathrm{DIN}$ (dissolved inorganic nitrogen, $\mathrm{NH}_{4}{ }^{+}+\mathrm{NO}_{3}{ }^{-}+$

$653 \mathrm{NO}_{2}^{-}$), Tur (turbidity), DO (dissolved oxygen), Sal (salinity), Tem (temperature), and Lng (longitude).

654

655 Fig. 6 Location map with labeled coral reef areas including 6 sampling sites in the South China Sea.

656 The map was constructed using ArcGIS software (ver. 10.1). The offshore reef area was drawn using

657 remote sensing images (fusion of Landsat 8 multispectral bands and a panchromatic band) with a 658 resolution of 15 meters.

659

660

661

662

663

664

665

666 


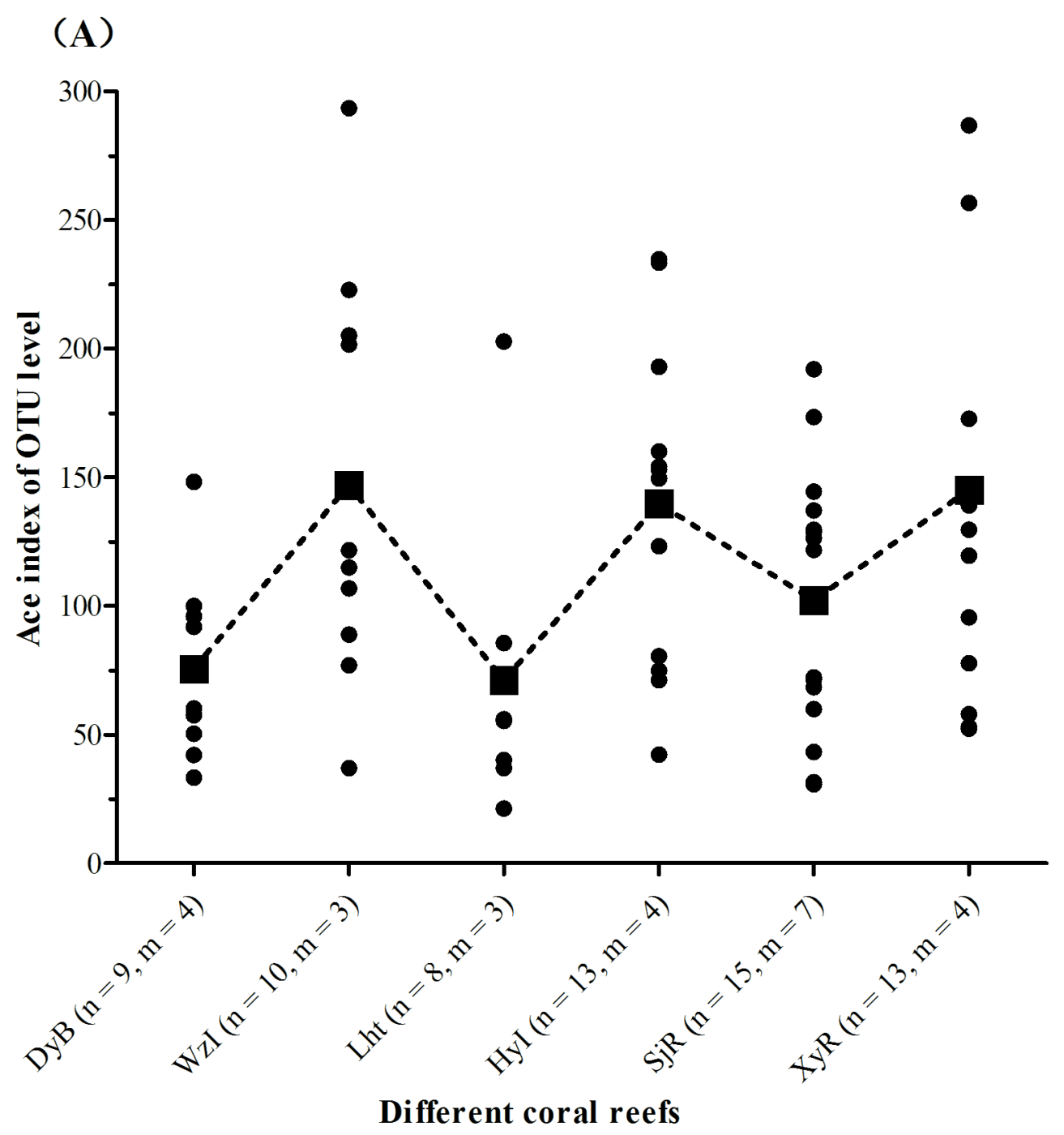




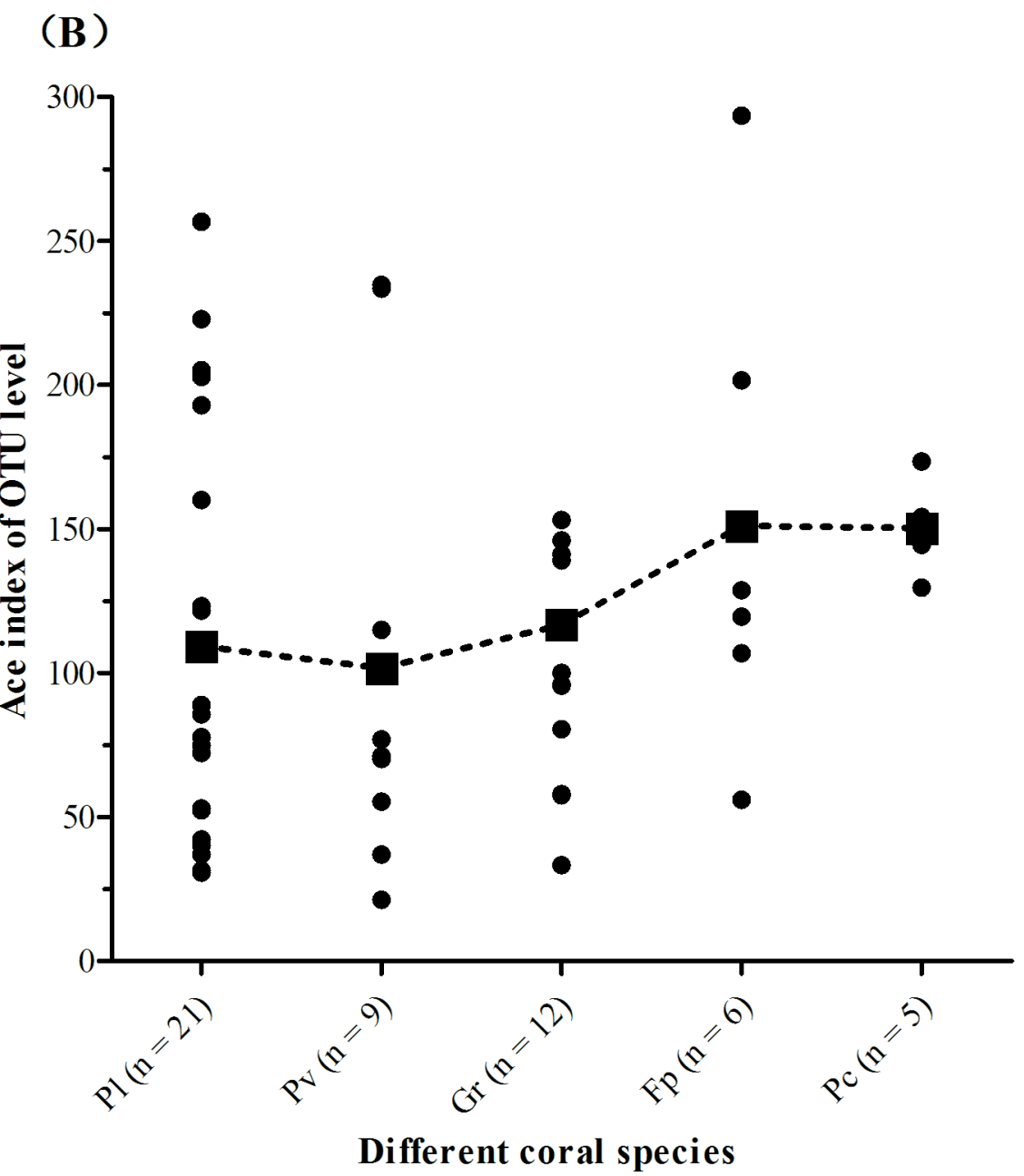


(C)

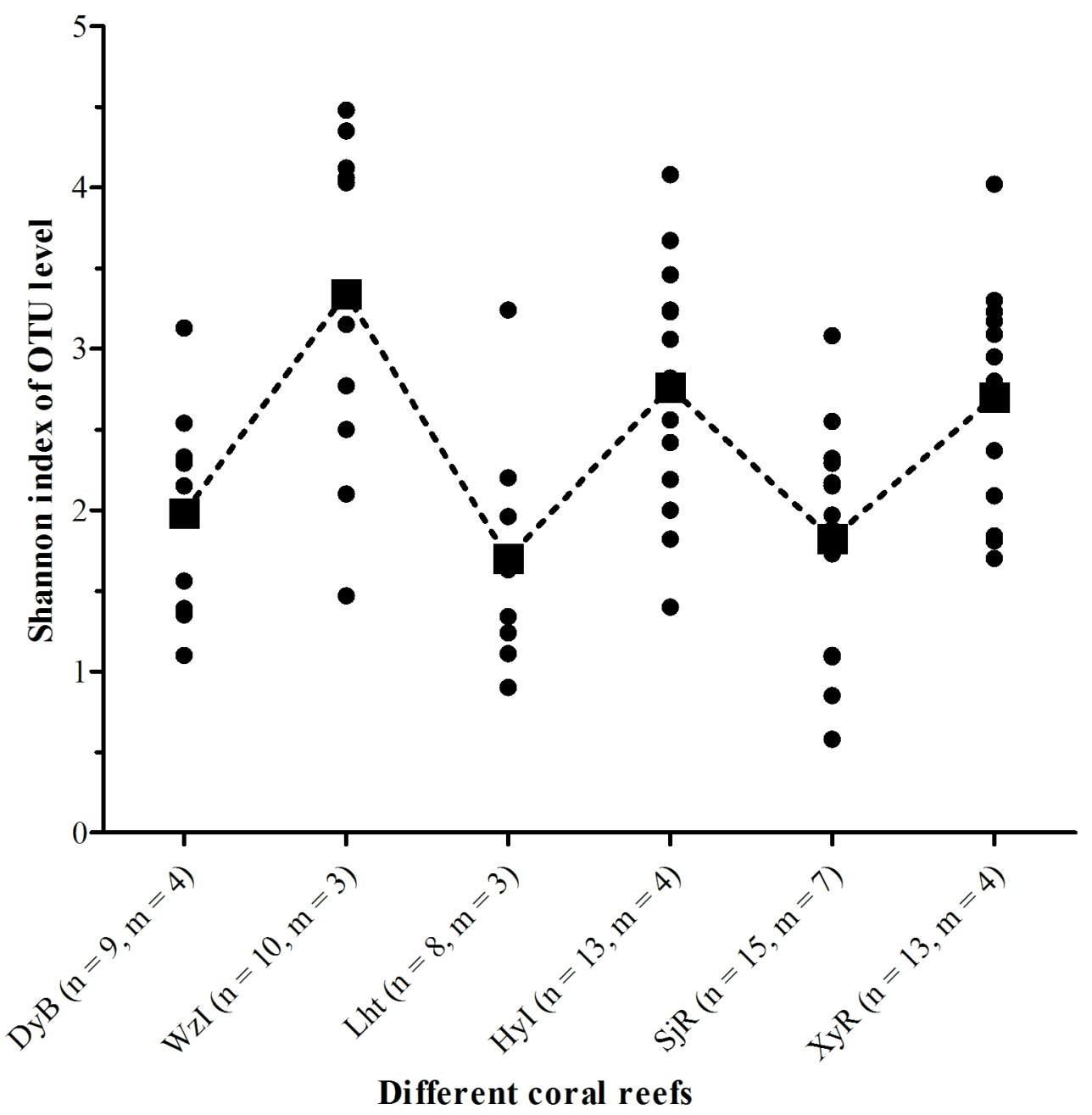

670 
(D)

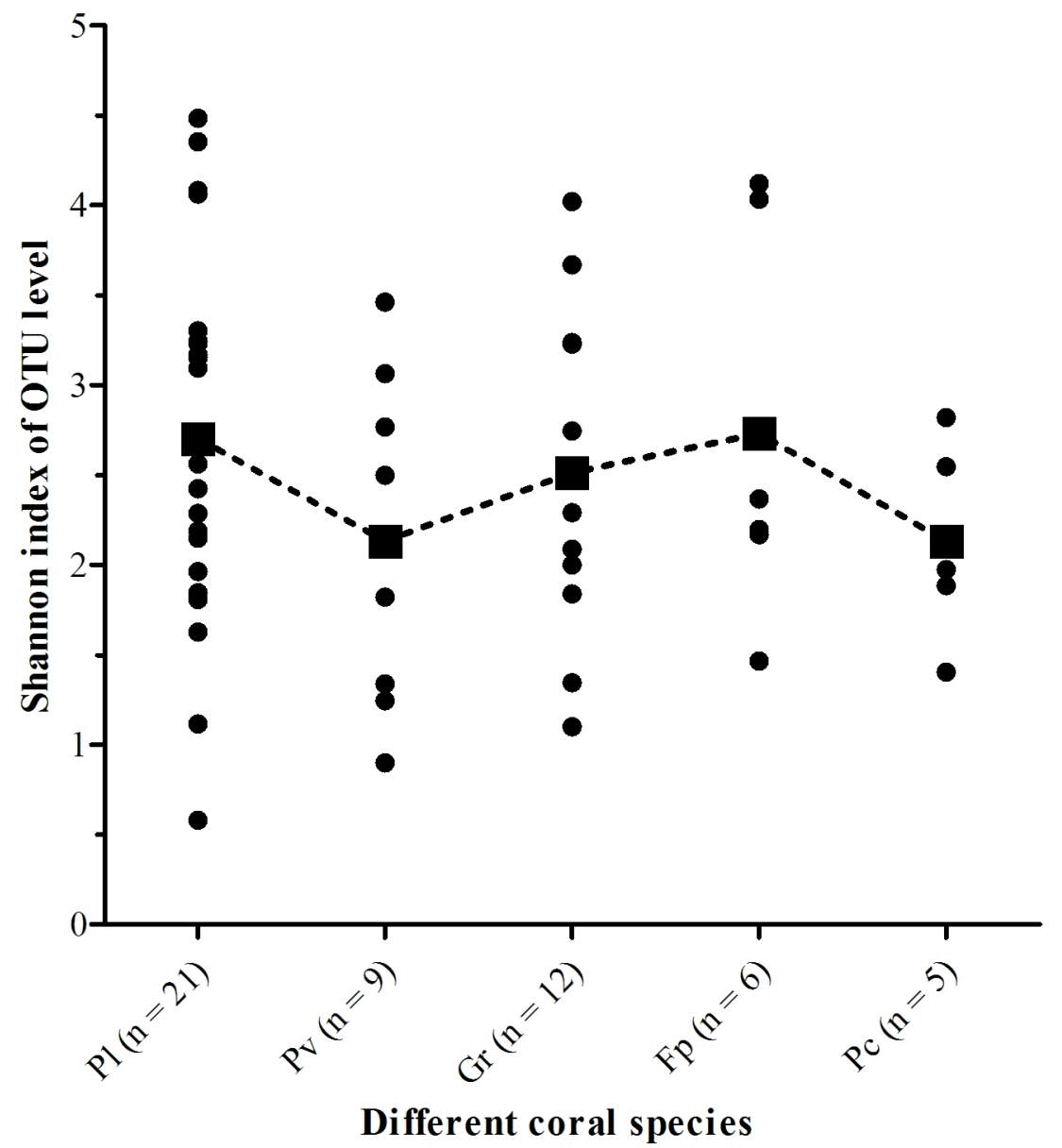

671

672

673

674

675

676

677

678

679

680

681 
Fig. 2

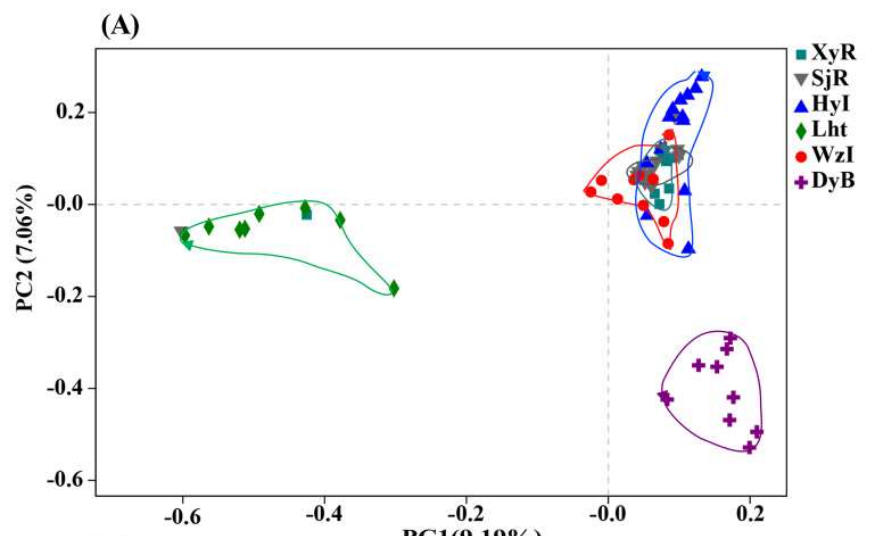

(B)

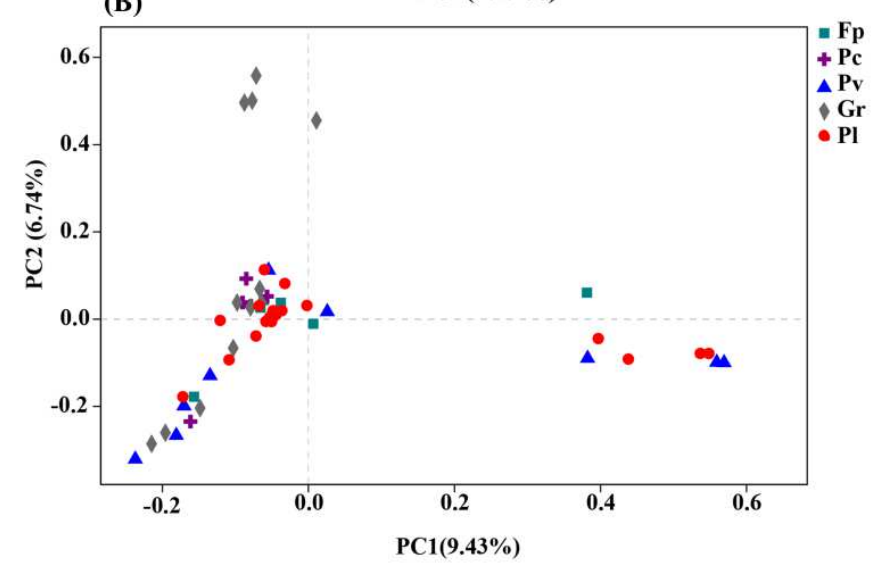

683

684

685

686

687

688

689

690

691

692

693

694 
Pl1 WzI 7 Par

Pv1_WzI

PI2_WzI

Pl3_WzI

Py2 W W I

Pv3 3 W

Pl4_WZI Da

Fp1_WzI -

Fp2_WzI - a new

Fp3_WzI

$\mathrm{Pl} 5 \mathrm{HyI}$

Gr3_Hyl

Pc2_Hyl

Pv2_Hyl

Pl1_HyI

Gr1_HyI

Pl3_Hyl $\mathrm{Pl}$ Hyl

Gr2_HyI

Pv1_HyI

PI4_HyI

Pcl Hyl

Pv3_Hyl

Pv1_Lht

Pl1_Lht _ D

Fp1_Lht

$\mathrm{Pl} 2$ Lht

Pv2_Lht

P13_Lht _ PV

Pv3_Lht

P Pl4_Lht

PI2 XyR

Pl3_XyR

P14_XyR

Gr1_XyR__n

Gr2 XyR

Arl XyR

Ar3_XyR

Gr5_XyR

Gr4_XyR -

Fpl_XyR -

Ar2 XyR -

Gr3 XyR

Gri_DyB

Hm1_DyB

Pd1_DyB -

d2 2 DyB

Gr3 DyB

Gf1_DyB

Gr2_DyB -

Gr4_DyB

Gf2_DyB D

$\mathrm{PII}$ SjR

$\mathrm{Pl} 2 \mathrm{SjR}$

$\mathrm{Mel}$-SjR

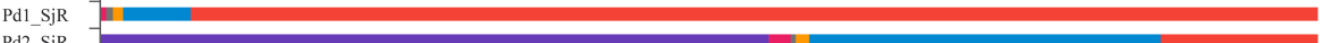

$\mathrm{Pd} 2 \mathrm{SjR}$ -

$\mathrm{Pl} 4 \mathrm{SjR}$ -

Hm1_SjR

$\mathrm{Pe} 1$ _SjR

Hm2_SjR

$\mathrm{Me} 2 \mathrm{SjR}$

Fpl_SjR

$\mathrm{Pcl} \mathrm{SjR}$

$\mathrm{Pc} 2_{2} \mathrm{SjR}$

Pc3_SjR

$\mathrm{Pl} 3 \mathrm{SjR}$

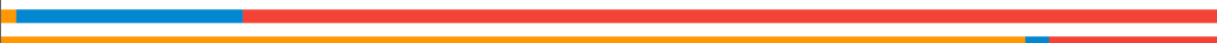

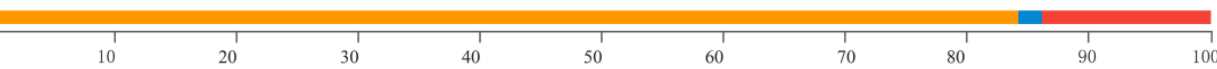

Percent of community abundance on Phylum level (\%)

unclassified Bacteria I $\square$ Proteobacteria $\square$ Chlorobi $\square$ unclassified Bacteria $I I \square$ Cyanobacteria

marine_stromatolite_eubacteria_ensemble $\quad$ unclassified Bacteria III $\quad$ Euryarchaeota $\quad$ others 
Fig. 4

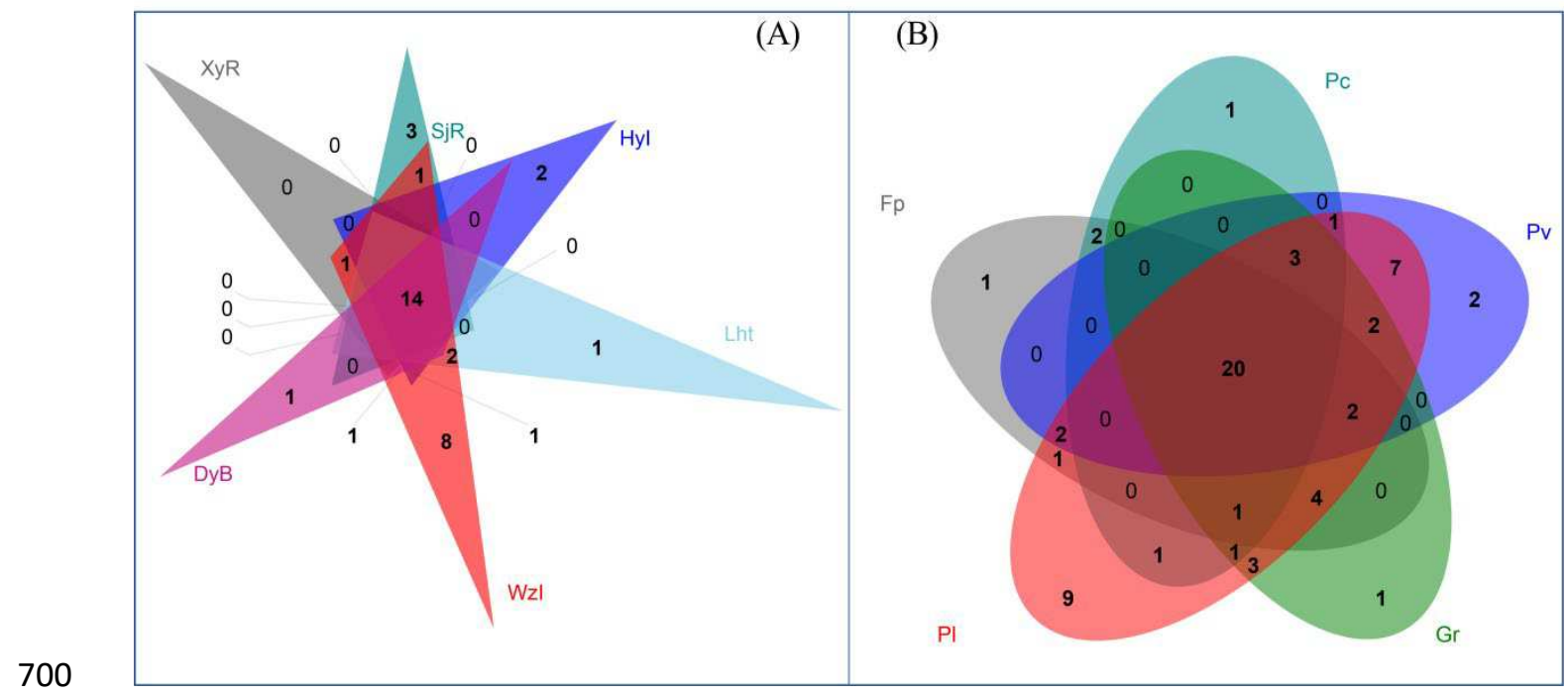

701

702

703

704

705

706

707

708

709

710

711

712

713

714

715 


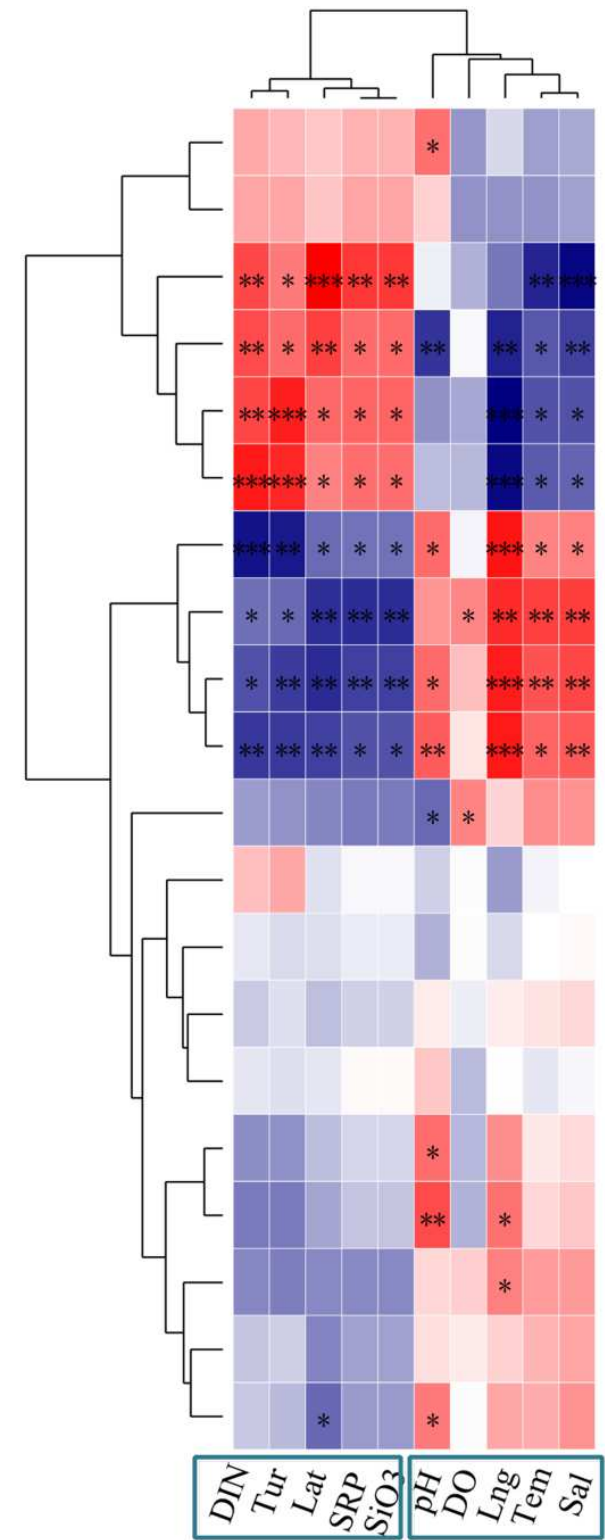

Group I

Group II
unclassified_c_Deltaproteobacteria

Klebsiella

unclassified_f_Chlorobiaceae

Chlorobium

unclassified_p_unclassified Bacteria II

unclassified_o Desulfuromonadales

unclassified_c_norank_p_Cyanobacteria

norank $\mathrm{p}$ unclassified Bacteria I

unclassified c Alphaproteobacteria

unclassified $\mathrm{p}$ _Cyanobacteria

Leptolyngbya

norank_p_unclassified Bacteria II

unclassified_c_Gammaproteobacteria

Pseudomonas

0.2

unclassified_o_Chromatiales

unclassified_o_Rhizobiales

unclassified_f_Chromatiaceae

norank_c_unclassified_Cyanobacteria

unclassified_k_norank_d_Bacteria

unclassified_p_Proteobacteria

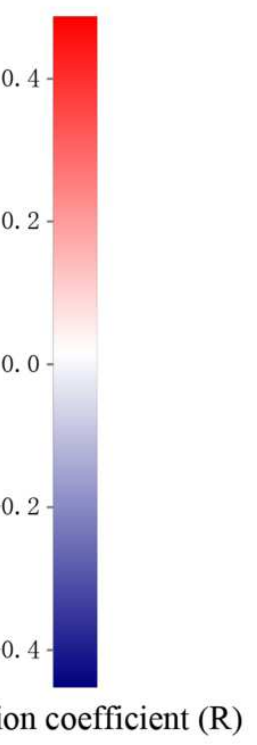

Correlation coefficient (R) 
Fig. 6

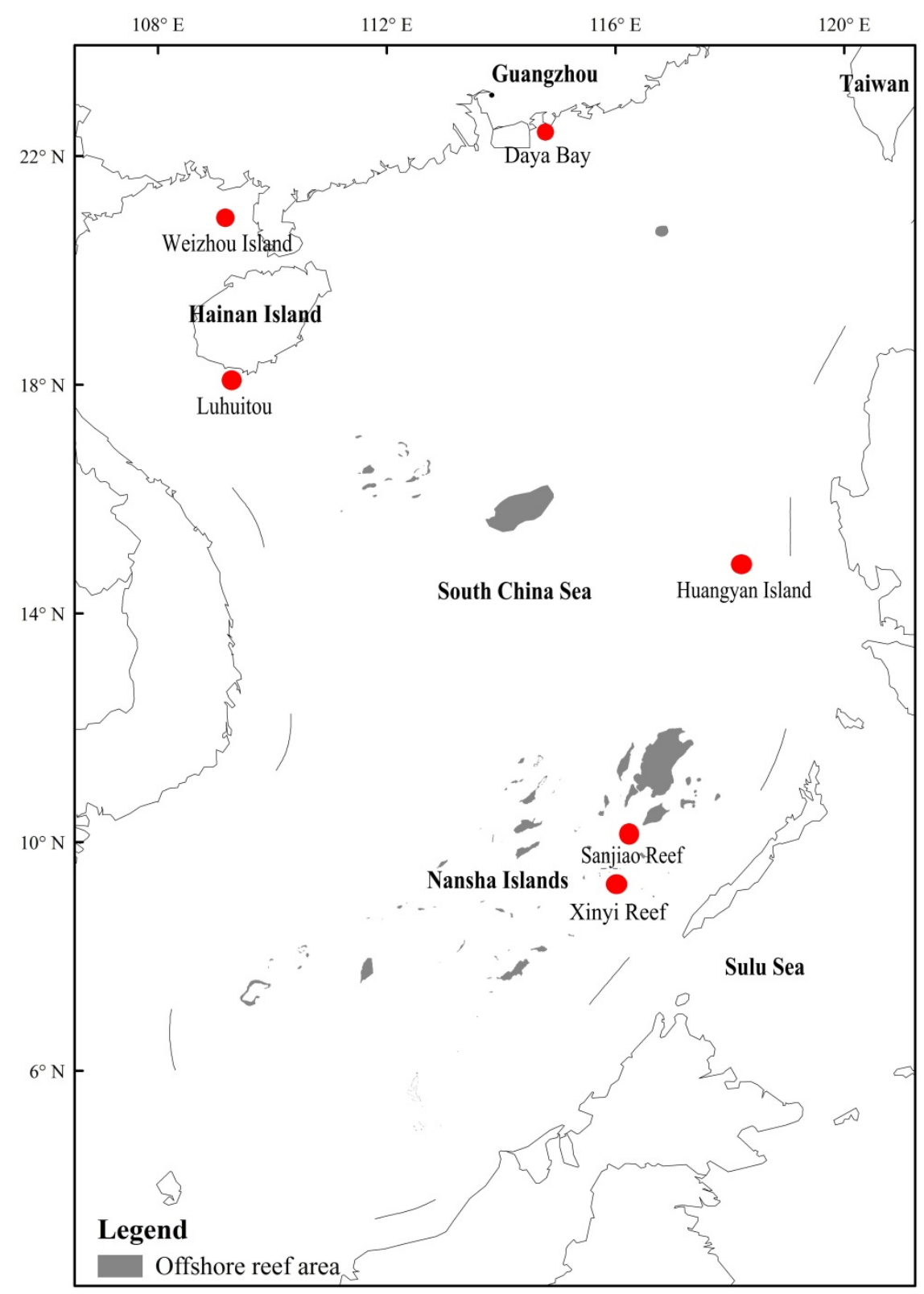

725 


\section{Figures}
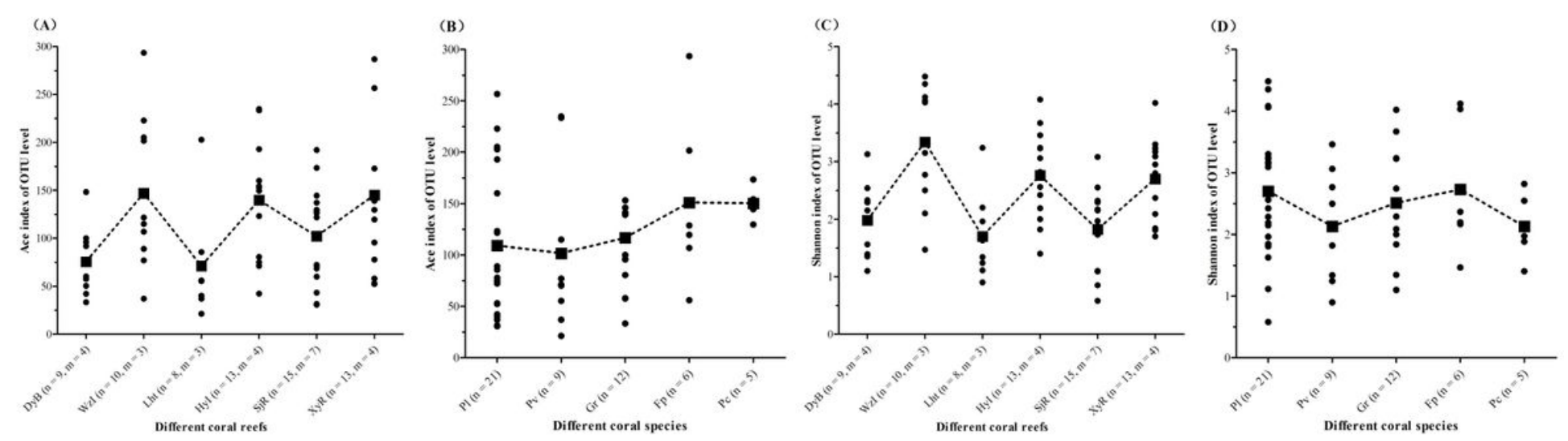

Figure 1

Test for differences in alpha-diversity indices of coral-associated diazotrophs between sample groups at the OTU level. (A) ACE between coral reefs, (B) ACE between coral species, (C) Shannon index between coral reefs, and (D) Shannon index between coral species. The test used was Student's t-test. The black

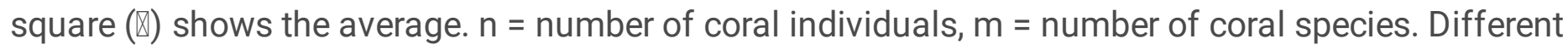
coral reefs are represented in (A) and (C) by the abbreviations DyB (Daya Bay), Hyl (Huangyan Island), Lht (Luhuitou), SjR (Sanjiao Reef), XyR (Xinyi Reef), and Wzl (Weizhou Island); different coral species in (B) and $(D)$ are represented by the abbreviations PI (Porites lutea), Pv (Plesiastrea versipora), Fp (Favia palauensis), Gr (Goniastrea retiformis), and Pc (Plesiastrea curta). 
(A)
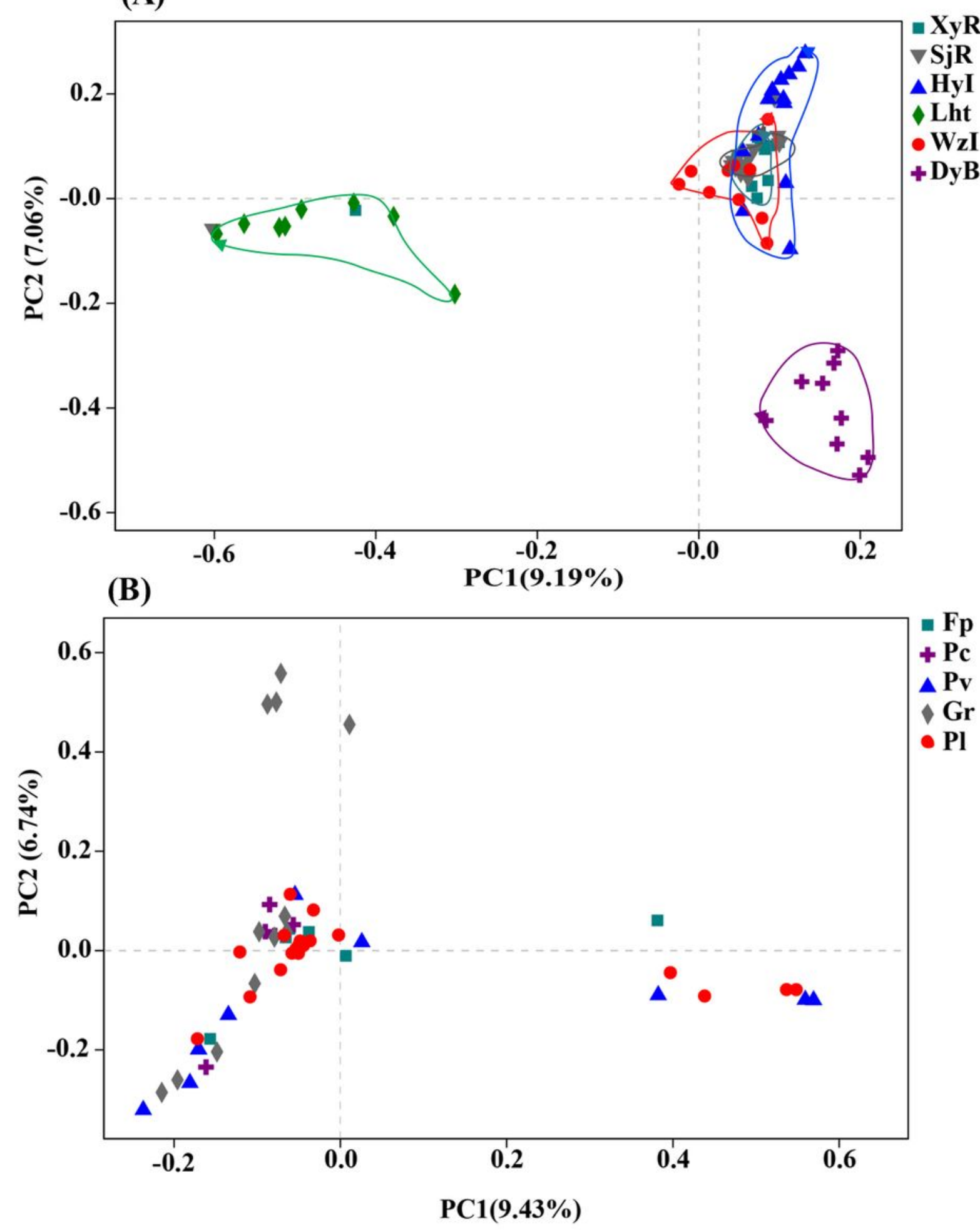

Figure 2

PCoA plot at the OTU level of all the coral samples collected from six different coral reefs. Coral samples were grouped according to $(A)$ collection site and or (B) species with $\geq 5$ colonies from the same coral reef. Scatter plot showing principal coordinate 1 (PC1) vs principal coordinate 2 (PC2). PC1 and PC2 represent the principal factors affecting the composition of coral-associated diazotrophs. Abbreviations are the same as in Fig. 1. 
PII_WzI

Pv1_Wzl

Pl2_WzI

Pl3_WzI

Pv2_Wzl

Pv3_WzI

$\mathrm{P} 14$ W
Fpl W
W

Fp2 W2l

Fp3_WzI

PI5_Hyl

Gr3_Hyl

Pc2 Hyl

Pv2_HyI

PII_HyI

Grl_Hyl

P13_Hyl

PI2_Hyl

Gr2_Hyl

PvI_Hyl

P14_Hyl

Pel_Hyl

Pv3_Hyl

Pvi_Lht

PI1_Lht

Fpl_Lht

P12_Lht

P13_Lht

Pv3_Lht

3 P14_tht

差 PII_XyR

PI3 XyR

퐁 PI4_XyR

Gri_XyR

Gr2_XyR

Arl XyR

Ar3_XyR

Gr5_XyR

Gr4_XyR

Fpl_XyR

Gr 3 XyR

Gri_DyB

HmI_DyB

PdI_DyB

Pd2_DyB

Gr3_DyB

GfI_DyB

Gr2 DyB

Gr4_DyB

Gf2_DyB

PI2_SjR

Mel_SjR

PdI_SjR

$\mathrm{Pd} 2 \_\mathrm{SjR}$

Pl4_SjR

HmI_SjR

$\mathrm{Pel} \_\mathrm{SjR}$
$\mathrm{Hm} 2 \mathrm{SjR}$

$\mathrm{Hm} 2 \mathrm{SjR}$
$\mathrm{Me} 2 \mathrm{SjR}$

Fpl_SjR

Pel_SjR

Pe2_SjR

Pc3_SjR

Pl3_SjR

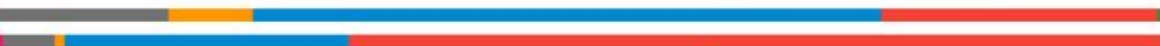

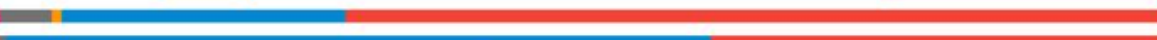
(20) (n) (2)

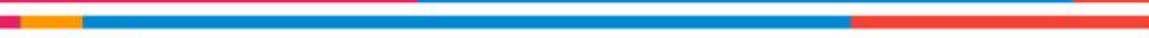

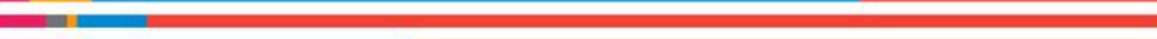

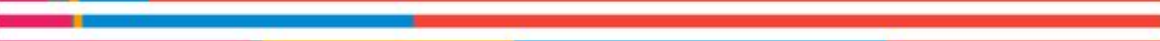

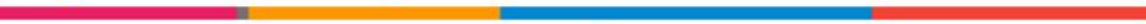

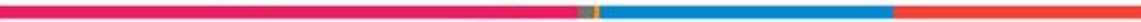

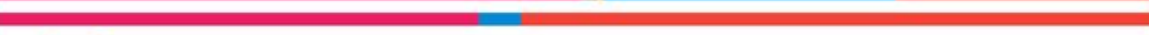

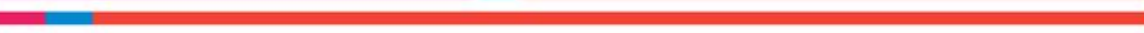
(20) (19)

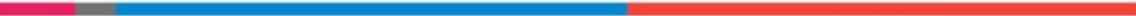
(2) =

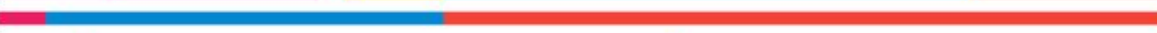
(20) (20) 每 -

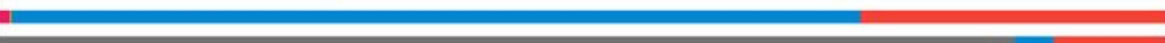
(20)

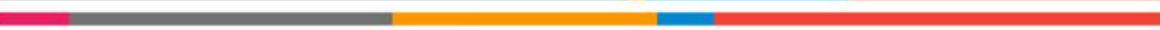

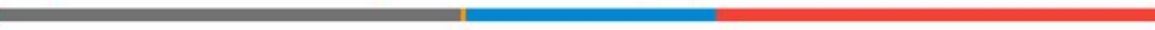

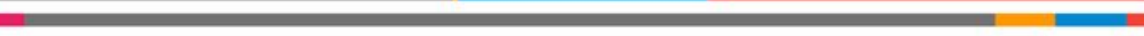
-

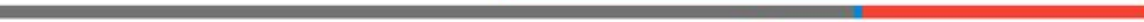
(2) (2) (20) (1)

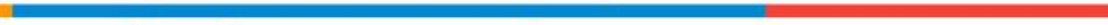
(2) (20)

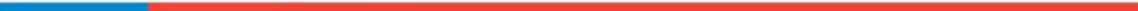
(2)

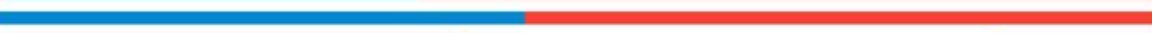
(2) (1)

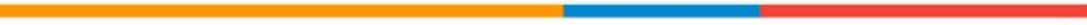
俉

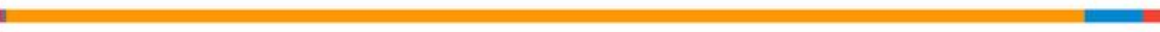
(2) (1) a

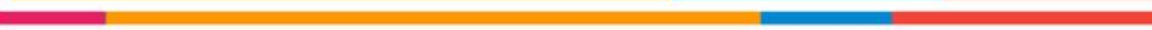
(1) (20)

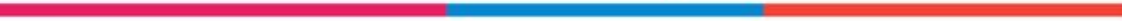

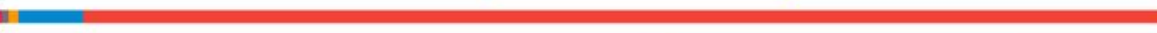
(20) 每 - nes

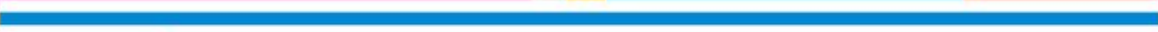

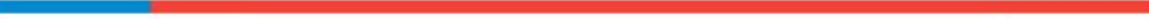

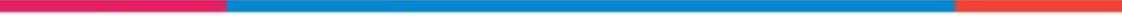

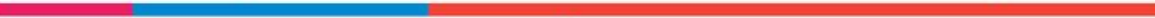

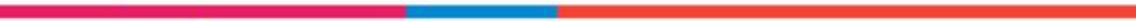
(1)

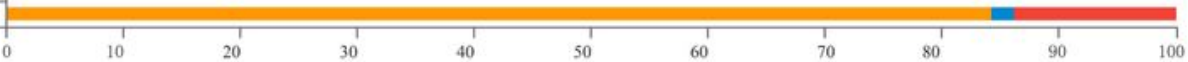
Percent of community abundance on Phylum level (\%)

unclassified Bacteria I $\square$ Proteobacteria $\quad$ Chlorobi $\square$ unclassified Bacteria $\|$

marine stromatolite eubacteria ensemble $\quad$ unclassified Bacteria III $\quad$ Euryarchacota $\square$ others

Figure 3

Composition profiles of diazotrophs. Taxonomic classification of bacterial reads retrieved from all the coral samples at the phylum level using RDP Classifier. 


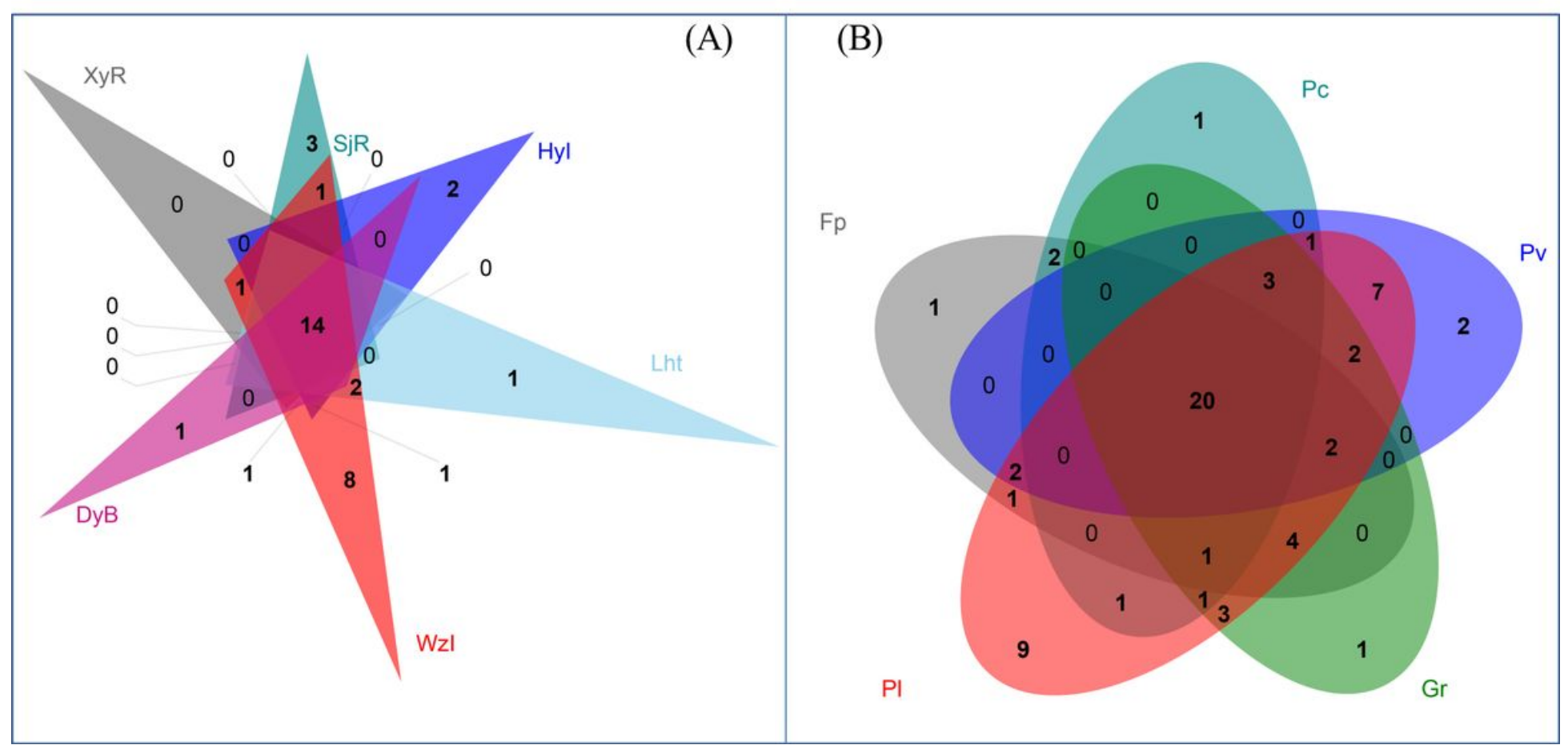

Figure 4

Venn diagrams showing the number of diazotrophs at the genus level from different coral reefs $(A)$ and coral species (B). Abbreviations are the same as in Fig. 1. 


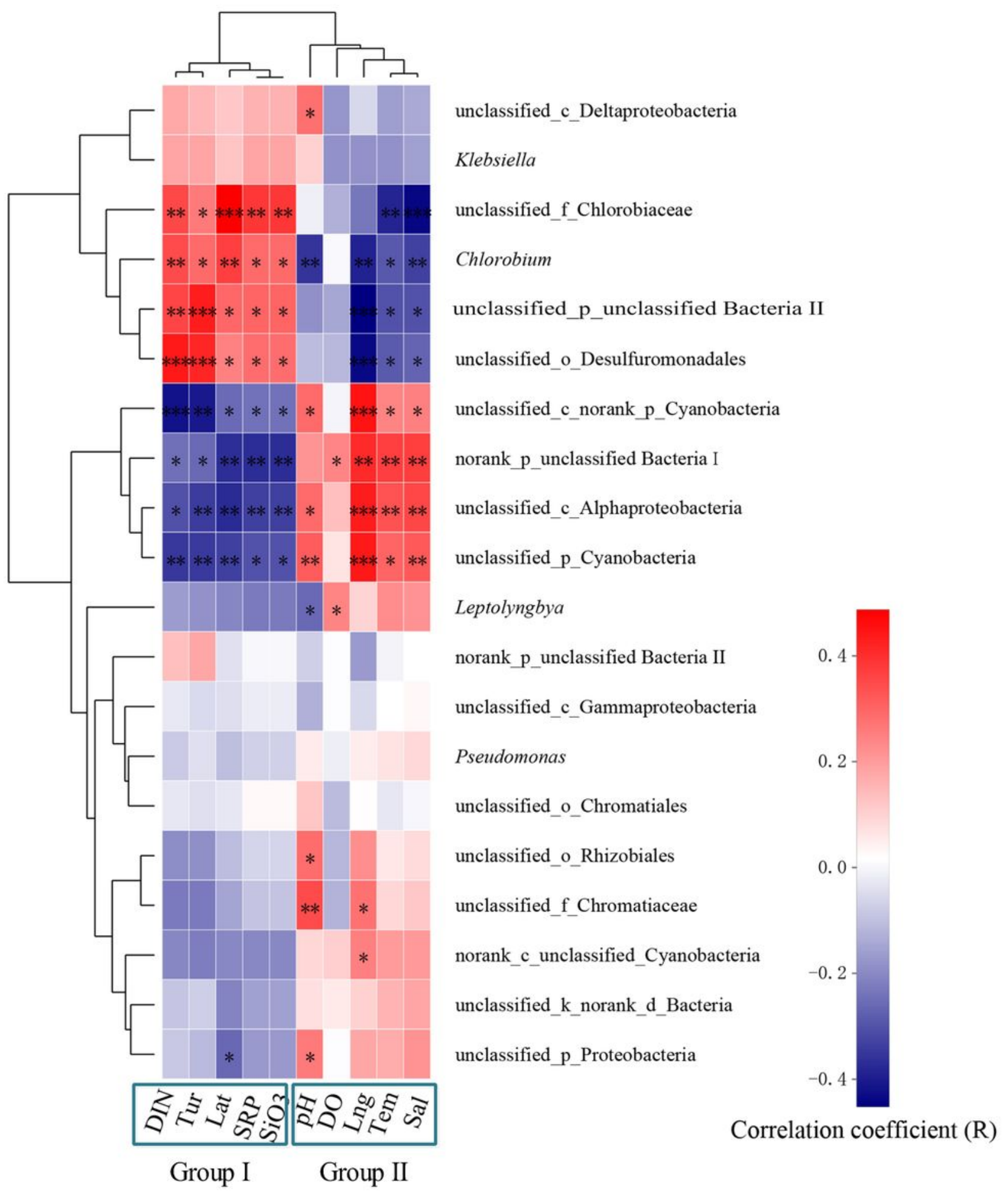

\section{Figure 5}

Correlation analyses between environmental parameters and populations of diazotrophs at the genus level. The diazotrophs analyzed were the top 20 genera in terms of total abundance. Hierarchical clustering of environmental variables was performed based on the raw data, while diazotrophic species were clustered based on averages. Significant differences are indicated by different numbers of asterisks $(0.01<p \leq 0.05 *, 0.001<p \leq 0.01 * *, p \leq 0.001 * \star *)$. Nonsignificant correlations do not have an asterisk. 
The $\mathrm{R}$ value represents the correlation coefficient, and the closer it is to 1 , the more significant the correlation is. Some of the environmental variables are represented by abbreviations, including Lat (latitude), SRP (PO43-), SiO3 (SiO32-), DIN (dissolved inorganic nitrogen, NH4+ + NO3- + NO2-), Tur (turbidity), DO (dissolved oxygen), Sal (salinity), Tem (temperature), and Lng (longitude). 